\title{
Spatial synchrony in the response of a long range migratory species (Salmo salar) to climate change in the North Atlantic Ocean
}

Olmos, Maxime; Payne, Mark R; Nevoux, Marie; Prévost, Etienne; Chaput, Gérald; Du Pontavice, Hubert; Guitton, Jérôme; Sheehan, Timothy; Mills, Katherine; Rivot, Etienne

\author{
Published in: \\ Global Change Biology \\ Link to article, DOI: \\ $10.1111 / \mathrm{gcb} .14913$ \\ Publication date: \\ 2020 \\ Document Version \\ Peer reviewed version \\ Link back to DTU Orbit
}

Citation (APA):

Olmos, M., Payne, M. R., Nevoux, M., Prévost, E., Chaput, G., Du Pontavice, H., Guitton, J., Sheehan, T., Mills, K., \& Rivot, E. (2020). Spatial synchrony in the response of a long range migratory species (Salmo salar) to climate change in the North Atlantic Ocean. Global Change Biology, 26(3), [1319-1337]. https://doi.org/10.1111/gcb.14913

\section{General rights}

Copyright and moral rights for the publications made accessible in the public portal are retained by the authors and/or other copyright owners and it is a condition of accessing publications that users recognise and abide by the legal requirements associated with these rights.

- Users may download and print one copy of any publication from the public portal for the purpose of private study or research.

- You may not further distribute the material or use it for any profit-making activity or commercial gain

- You may freely distribute the URL identifying the publication in the public portal 
DR. MAXIME OLMOS (Orcid ID : 0000-0002-0425-0600)

DR. HUBERT DU PONTAVICE (Orcid ID : 0000-0001-9571-0651)

Article type : Primary Research Articles

\section{Spatial synchrony in the response of a long range migratory species (Salmo salar) to climate change in the North Atlantic Ocean}

Maxime Olmos ${ }^{1,2, \#}$, Mark R. Payne ${ }^{3}$, Marie Nevoux ${ }^{1,2}$,Etienne Prévost ${ }^{2,4}$, Gérald Chaput ${ }^{5}$, Hubert

Du Pontavice ${ }^{1,6}$, Jérôme Guitton ${ }^{1}$, Timothy Sheehan ${ }^{7}$, Katherine Mills ${ }^{8}$, and Etienne Rivot ${ }^{1,2, \# \# ~}$

${ }^{1}$ UMR ESE, Ecology and Ecosystem Health, Agrocampus Ouest, INRA, 35042 Rennes, France

${ }^{2}$ Management of Diadromous Fish in their Environment, AFB, INRA, Agrocampus Ouest, UNIV PAU \& PAYS ADOUR/E2S UPPA, Rennes, France.

${ }^{3}$ National Institute for Aquatic Resources, Technical University of Denmark (DTU-Aqua), 2800 Kongens Lyngby, Denmark.

${ }^{4}$ ECOBIOP, INRA, Univ. Pau \& Pays Adour / E2S UPPA, 64310 Saint-Pée-sur-Nivelle, France

${ }^{5}$ Fisheries and Oceans Canada, 343 University Avenue, Moncton, NB, E1C9B6, Canada

${ }^{6}$ Nippon Foundation-Nereus Program, Institute for the Oceans and Fisheries, University of British Columbia, Vancouver, British Columbia, Canada

${ }^{7}$ Northeast Fisheries Science Center, National Marine Fisheries Service, 166 WaterStreet, Woods Hole, MA 02543, USA

This article has been accepted for publication and undergone full peer review but has not been through the copyediting, typesetting, pagination and proofreading process, which may lead to differences between this version and the Version of Record. Please cite this article as doi: 10.1111/GCB.14913

This article is protected by copyright. All rights reserved 
${ }^{8}$ Gulf of Maine Research Institute, 350 Commercial Street, Portland, ME 04101, USA

Corresponding authors: \# olmosmaxim@gmail.com, \#\# etienne.rivot@agrocampus-ouest.fr 


\section{ABSTRACT}

A major challenge in understanding the response of populations to climate change is to separate the effects of local drivers acting independently on specific populations, from the effects of global drivers that impact multiple populations simultaneously and thereby synchronize their dynamics. We investigated the environmental drivers and the demographic mechanisms of the widespread decline in marine survival rates of Atlantic salmon (Salmo salar) over the last four decades. We developed a hierarchical Bayesian life cycle model to quantify the spatial synchrony in the marine survival of 13 large groups of populations (called stock units, SU) from two continental stockgroupings (CSG) in North America (NA) and Southern Europe (SE) over the period 1971-2014. We found strong coherence in the temporal variation in post-smolt marine survival among the 13 SU of NA and SE. A common North Atlantic trend explains $37 \%$ of the temporal variability of the survivals for the $13 \mathrm{SU}$ and declines by a factor 1.8 over the 1971-2014 time series. Synchrony in survival trends is stronger between SU within each CSG. The common trends at the scale of NA and SE capture $60 \%$ and $42 \%$ of the total variance of temporal variations, respectively. Temporal variations of the post-smolt survival are best explained by the temporal variations of sea surface temperature (SST, negative correlation) and net primary production indices (PP, positive correlation) encountered by salmon in common domains during their marine migration. Specifically, in the Labrador Sea/Grand Banks for NA populations $26 \%$ and $24 \%$ of variance is captured by SST and PP, respectively and in the Norwegian Sea for SE populations $21 \%$ and $12 \%$ of variance is captured by SST and PP, respectively. The findings support the hypothesis of a response of salmon populations to large climate induced changes in the North Atlantic simultaneously impacting populations from distant continental habitats.

Key words: Spatial covariation, climate change, stage-based life cycle model, marine survival, Atlantic salmon, environmentally driven changes, bottom-up, hierarchical Bayesian model 


\section{INTRODUCTION}

Understanding the response of populations to global changes, in terms of demography and adaptive capacity, is critical to support ecosystem-based management (Brown et al., 2011; Edwards, Beaugrand, Hays, Koslow, \& Richardson, 2010; Harley et al., 2006; Stenseth, 2002). A major challenge to understanding the response of populations to environmental variations is to partition the effects of global drivers that likely impact multiple populations simultaneously and synchronize their dynamics from the effects of drivers acting locally on specific populations (Moran, 1953; Post \& Forchhammer, 2002). This is also critical for a better understanding of the mechanisms affecting the resilience of populations to global change (Heino, 1998; Palmqvist \& Lundberg, 1998).

Life cycle models that consider and incorporate the spatial and temporal heterogeneity of ecological mechanisms and demographic responses are useful for examining the effects of multiple factors that interact in a hierarchy of scales (Cunningham, Westley, \& Adkison, 2018; Rochette, Le Pape, Vigneau, \& Rivot, 2013; Stelzenmüller, Schulze, Fock, \& Berkenhagen, 2011). When combined with the analysis of multiple populations, these models provide a powerful approach to partition the effects of factors impacting each population specifically from those affecting groups of populations simultaneously (Lahoz-Monfort et al. 2013; Walter et al. 2017). In addition, signals that arise from multiple population relationships are more likely to represent true biological processes rather than statistical flukes (Myers, Mertz, \& Bridson, 1997; Soberon \& Nakamura, 2009) and as a result can be more informative than separate analyses of single populations (Britten, Dowd, \& Worm, 2016; Szuwalski, Vert-Pre, Punt, Branch, \& Hilborn, 2015; Zimmermann, Claireaux, \& Enberg, 2019).

Separating out the different scales of interactions of ecological processes driving population dynamics is particularly challenging in the case of highly migratory species, which can interact with a multitude of single and/or synergistic factors at different points in time and space during their life cycle. For instance, the life cycle of anadromous fish, such as salmonids, relies on population-specific freshwater habitats for reproduction and juvenile growth and marine habitats shared by multiple populations for feeding and maturation. This makes these species sensitive to multiple environmental and anthropic stressors acting at different spatial scales, with factors 
operating at sea potentially having synchronizing effects on the dynamics of large groups of populations. For such species, identifying the space and time domains associated with specific life stages that are most susceptible to conditioning the population dynamics is a prerequisite to better understand population responses to global changes (Cunningham et al., 2018) and to support improved management decisions and actions at global and local scales.

Atlantic salmon (Salmo salar) is one of the most emblematic fish in the Atlantic Ocean. The species reproduces in a large number $(\sim 2000)$ of rivers distributed in the eastern (Europe) and western (North America) regions of the North Atlantic. Due to its highly evolved homing ability, the species is structured into individual river populations, with specific and variable freshwater habitat environments. During the freshwater phase, the population dynamics are conditioned by local habitat quality and trophic resources (Elliott, 2001; Jonsson, Jonsson, \& Hansen, 1998; Milner et al., 2003). During the marine phase, populations originating from distant continental habitats migrate to common feeding grounds in the North Atlantic, with major concentrations located off West Greenland, in the Labrador Sea, and the Faroes Islands and Norwegian Sea (Aas, Einum, Klemetsen, \& Skurdal, 2010; D. H. Mills, 1989). In these aggregations at sea, they are exposed to common environmental marine conditions and fisheries.

Atlantic salmon populations from North America and Europe have undergone a widespread decline in abundance over the last four decades (Chaput, 2012; ICES, 2017; Olmos et al., 2019), but the mechanisms responsible for these declines are still unclear. The broad scale pattern of decline has led to the hypotheses that major ecosystem changes in the North Atlantic Ocean are the main driver of these declines (Olmos et al., 2019). The mechanisms for this may include an indirect effect associated with an increase in sea temperatures (Beaugrand \& Reid, 2012; Friedland, Moore, \& Hogan, 2009; Jensen et al., 2012). A major trophic shift in the North Atlantic Ocean was documented in the early 1990's with trophic level changes observed in the plankton communities upward to seabird populations (Beaugrand, Edwards, Brander, Luczak, \& Ibanez, 2008; Durant, Anker-Nilssen, \& Stenseth, 2003; A. J. Pershing, Head, Greene, \& Jossi, 2010) which was hypothesized to exert bottom up control via reductions in the abundances and the energetic value of prey across higher trophic levels (K. E. Mills, Pershing, Sheehan, \& Mountain, 2013; Otero et al., 2012; Renkawitz, Sheehan, Dixon, \& Nygaard, 2015). These changes may have been responsible for altered Atlantic salmon growth at sea and consequently survival through 
size-dependent mortality (Friedland \& Reddin, 2000; Gislason, Daan, Rice, \& Pope, 2010; Peyronnet, Friedland, Maoileidigh, Manning, \& Poole, 2007).

Broader scale analyses to date, however, suggest that despite the overall spatial coherence of the trends in abundances and survival rates observed throughout the North Atlantic, the annual and region specific variations between continental stock groups (CSG) in North America and Southern Europe and among populations within a CSG are large (Olmos et al., 2019). This may in part be explained by the diversity and complexity of migration routes at sea undertaken by populations originating from different areas of the North Atlantic. As such, it is challenging yet necessary to identify the space and time domains along the migration routes at sea where salmon are exposed to favorable and unfavorable ecosystem conditions that may strongly affect their survival.

Although the early Atlantic salmon post-smolt marine phase is often suggested as a critical stage for survival (Friedland et al. 2003a, 2005, 2000; Thorstad et al. 2012; Chaput et al. 2018), the environmental conditions encountered later in the first year at sea can also be important (Friedland et al., 2009; Friedland \& Reddin, 2000; K. E. Mills et al., 2013). In addition, the factors involved in the declines in survival may differ between populations. Growth variations during the first summer at sea have been hypothesized as critical for the survival of SE populations (Friedland et al. 2008; Friedland et al. 2014; McCarthy, Friedland, and Hansen 2008; Peyronnet et al. 2007; Haugland et al. (2006) and Jensen et al. (2012)). In contrast, variations in predation pressure in early spring have been hypothesized to be the main driver of early post-smolt survival in southern NA populations (Friedland et al., 2014).

The mechanisms involved at various spatial and temporal scales, and the degree to which these mechanisms and hence the responses are shared between populations remain largely unclear. A simultaneous and joint analysis of multiple populations throughout the Atlantic Ocean within a unified framework is needed to improve our understanding of the response of Atlantic salmon populations to changes in the marine ecosystem.

In this paper, we rely on the modelling framework developed by Olmos et al. (2019) to explore how environmental conditions encountered by Atlantic salmon in different space and time domains along the marine migration routes may contribute to the variations of marine survival in Europe and North America. Olmos et al. (2019) developed an age and stage-based model for the collective analysis of the dynamics of thirteen geographically proximate Atlantic salmon stock 
units (SU) from the eastern NA and SE CSG, and applied this model to data over the period 19712014. The model provides a framework to quantify the spatial coherence in the temporal variation of the post-smolt marine survival rates and in the proportion of fish maturing after one winter at sea (1SW) in a hierarchy of spatial scales across the North Atlantic. Olmos et al. (2019) reported on the strong coherence in temporal variation of marine survivals among the 13 stock units of Southern Europe and North America, represented by a collective decline in the marine survival over the 1971-2014 time series. The results also provided evidence of covariation among geographically proximate stock units, with the strength of the covariation that increases when going down to spatial scale, thus suggesting the intricate influence of drivers acting at a hierarchy of spatial scale.

Here, by taking advantage of the flexibility of the hierarchical model structure, we first extend the modelling framework developed by Olmos et al. (2019) by explicitly modeling temporal variation in post-smolt survival as the sum of trends in a hierarchy of spatial scales across global to local SU-specific areas. This allows the investigation of the degree of synchrony in Atlantic salmon post-smolt survival and explicitly quantifies the amount of variance that is captured by trends at various spatial scales. Second, we investigate whether the temporal variation in the marine survival can be explained by environmental variation encountered by salmon during the early post-smolt marine phase when salmon use specific transit habitat, or during the later phase of the first year at sea when salmon of different areas aggregate at common feeding areas. We conducted an extensive review of the literature on post-smolt migration routes to define the space-time domains associated with the early marine phase (spatially specific to each SU or to small groups of SU with proximate freshwater habitat) and late phase of the first year at sea (feeding areas common to large groups of SU). We then assessed the relationships between the temporal variations of marine survival and environmental covariates defined in those space-time domains including sea surface temperatures, primary production indices, and large scale climate indices. Our prediction was that the environmental conditions encountered in the common feeding areas should explain the greatest part of the synchronous signal observed between the SUs, while environmental conditions encountered during the early marine phase in transit habitat would not explain the broader scale responses of these salmon populations. 


\section{MATERIALS AND METHODS}

\subsection{General Model Outline}

Below we provide the main outlines of the model. Further details can be found in Olmos et al. (2019).

The model is an age- and stage-based life cycle model (Fig. 1) that formulates the dynamics of all $\mathrm{SU}$ in a single hierarchical framework. The spatial structure of the model is unchanged from Olmos et al. (2019). The model considers thirteen stock units that each define assemblages of river-specific Atlantic salmon populations reproducing in the respective North American (NA) and Southern European (SE) CSG. The NA CSG consists of 6 SU (indexed by $r=1, \ldots, 6$ ). The SE CSG consists of $7 \mathrm{SU}$ (indexed by $r=7, \ldots, 13$ ) (Fig. 2).

The Atlantic salmon from a SU are considered to form a single homogeneous group with similar life history and migration routes at sea. Juvenile salmon produced in each SU migrate to the sea as smolts after 1 to 6 years in freshwater, with the proportions at age varying among SUs. The model draws on explicit hypotheses about the migration routes at sea that generate spatial segregation in salmon populations (Fig. 1 and 2). All salmon from NA and SE migrate from their specific coastal area to reach a common feeding ground in the Labrador Sea and the Norwegian Sea, respectively. After one winter spent at sea, some salmon mature and return to their natal river to spawn while non-maturing salmon migrate to West Greenland. The different SU in the model present two levels of aggregation (Fig. 1). During the first months at sea, post-smolts of different SU are assumed to occupy spatially different transit habitats. In the later phase of the first year at sea, they migrate to a shared feeding area common to all SU of the same CSG, and where they are exposed to high seas fisheries operating on mixed SU.

The model is formulated in a Bayesian hierarchical state-space framework (Parent and Rivot, 2012; Rivot et al., 2004) that incorporates stochasticity in population dynamics as well as observation errors. It assimilates information from the time series of data (1971 to 2014) collated by ICES WGNAS (Working Group on North Atlantic Salmon; ICES, 2015, 2017). These consist of: (i) annual estimates of the number of mature anadromous Atlantic salmon that return to each of 
the $13 \mathrm{SU}$, by $1 \mathrm{SW}$ and $2 \mathrm{SW}$ maiden sea-age classes; (ii) annual estimates of homewater catches for each SU by sea-age class; (iii) annual estimates of commercial catches for the mixed stock fisheries at sea operating sequentially on combinations of SU, and data on the SU origin of the catches (but see Olmos et al. 2019 for further details).

The model was primarily designed to estimate the abundance of salmon at various life stages along the life cycle, the exploitation rates in the fisheries, and two key parameters of the marine phase: the post-smolt marine survival rates (from out-migrating smolts to the 1 January of the first winter at sea, referred as the Pre Fishery Abundance stage, or PFA) and the proportions of fish maturing as $1 \mathrm{SW}$, for each year and each SU. It explicitly considers temporal covariation in those two key demographic parameters. For the present analysis, we keep the original covariation model for the proportion of fish maturing as $1 \mathrm{SW}$ as defined by Olmos et al. (2019), with temporal variations of this parameters modeled as a multivariate random walk in the logit scale. Random variations are drawn from multivariate Normal distribution with a $13 \times 13$ variance-covariance matrix. The model for temporal variation in post-smolt marine survival, which is the focus of this paper, is modified from Olmos et al. (2019), and temporal variation is modelled through an explicit decomposition of terms associated with the various spatial scales, as detailed hereafter.

\subsection{Investigating the spatial synchrony in marine survival}

\subsubsection{Hierarchical decomposition of the temporal variations of post-smolt survival}

Different models for the temporal variation of post-smolt marine survival are tested (Supp. Mat S1). In the reference model M1 (eq. (1), (2) and Tables 1, S1.1), temporal variation in post-smolt survival is explicitly written as the sum of three components to partition out the survival signal at three scales: a term capturing the synchronous signal between all SU, a term capturing the synchronous signal within each CSG, and a term for the remaining temporal variability specific to each SU.

Following the methodology developed by Grosbois et al. (2009) and Lahoz-Monfort et al. (2011, 2013), post-smolt survival $\theta_{t, r}$ (in the logit scale) at year $t$ in SU r within the CSG g (g=NA or SE) is modelled as the sum of independent normally distributed random terms: 
with $\beta_{r}$ an intercept that is constant for all years and $\left(\delta_{t}, \alpha_{g_{t}}, \varepsilon_{t, r}\right)$ that are identically and independently normally distributed random terms:

(2)

$$
\text { for all } t,\left\{\begin{array}{c}
\delta_{t} \sim N\left(0, \sigma_{\delta}^{2}\right) \\
\alpha_{g_{t}} \sim N\left(0, \sigma_{\alpha_{g}}^{2}\right) \\
\varepsilon_{t, r} \sim N\left(0, \sigma_{\varepsilon_{r}}^{2}\right)
\end{array}\right.
$$

Time series of $\delta_{t}$ and $\left(\delta_{t}+\alpha_{g_{t}}\right)$ characterize the synchronous part of the signal at two spatial scales. The $\delta_{t}$ 's capture the trend that is common to all SU over the North Atlantic Ocean. The $\delta_{t}$ $+\alpha_{g_{t}}$ 's characterize the amount of between year variation synchronous to all SU within each $\mathrm{CSG}, \mathrm{g}=\mathrm{NA}$ and $\mathrm{g}=\mathrm{SE} . \varepsilon_{t, r}$ are remaining random variations specific to each SU that characterize the asynchronous part of the signal. Priors on parameters are all weakly informative (Table 1).

Two embedded models of lower complexity were then considered (Supp. Mat. S1). Since Olmos et al. (2019) have shown that there are correlations between SU, models with no correlations between SU were not examined further. Analyses that considered environmental covariates were based on the most complete model M1.

\subsubsection{Quantifying synchrony}

The different random terms $\left(\delta_{t}, \alpha_{g_{t}}, \varepsilon_{t, r}\right)$ in eq. (1) are independent, therefore the total between year variance of the post-smolt survival time series of each SU $\left(\operatorname{logit}\left(\theta_{t, r}\right)\right)$, denoted $V_{t_{t} t_{r}}$, is the sum of the variance of the random terms:

$$
\operatorname{Var}_{\text {tot }_{r}}=\sigma_{\delta}^{2}+\sigma_{\alpha_{g}}^{2}+\sigma_{\varepsilon_{r}}^{2}
$$

where $\mathrm{g}=\mathrm{NA}$ for $\mathrm{r}=1, \ldots, 6$ and $\mathrm{g}=\mathrm{SE}$ for $\mathrm{r}=7, \ldots, 13$. 
Synchrony at different spatial scales was quantified by calculating the Inter-Class Correlation

(ICC) based on the ratio of inter-annual variances (Grosbois et al., 2009; Lahoz-Monfort et al., 2013, 2011). For each SU $r$, we calculated

$$
\begin{gathered}
I C C_{\delta_{r}}=\frac{\sigma_{\delta}^{2}}{V a r_{t o t_{r}}} \\
I C C_{g_{r}}=\frac{\sigma_{\delta}^{2}+\sigma_{\alpha_{g}}^{2}}{\operatorname{Var}_{t o t_{r}}} .
\end{gathered}
$$

(5)

where $\mathrm{g}=\mathrm{NA}$ for $\mathrm{r}=1, \ldots, 6$ and $\mathrm{g}=\mathrm{SE}$ for $\mathrm{r}=7, \ldots, 13 . I C C_{\delta_{r}}$ quantifies the amount of variance of the survival time series that is captured by the global trend component $\delta$. A large $I C C_{\delta_{r}}$ means that the variance of the shared component $\left(\sigma_{\delta}^{2}\right.$, synchronous part of the signal) is large relative to the total variance of the time series. $I C C_{g_{r}}$ quantifies the amount of variance that is captured by the continental trend $g$ to which the SU $r$ belongs.

We then calculated synchrony indices as the average of ICC values:

(6)

$$
\begin{aligned}
& \overline{I C C}_{\delta}=\text { mean }_{\text {all } r}\left(I C C_{\delta_{r}}\right), \\
& \overline{I C C}_{N A}=\text { mean }_{\text {all r in } N A}\left(I C C_{N A_{r}}\right), \\
& \overline{I C C}_{S E}=\text { mean all rin } S E_{\left(I C C_{S E_{r}}\right) .}
\end{aligned}
$$

$\overline{I C C_{\delta}}$ is the amount of temporal variance that is synchronous among all $\mathrm{SU}$ and provides a global index of synchrony over the entire set of SU in both NA and SE CSG. $\overline{I C C}_{N A}$ and $\overline{I C C}_{S E}$ are the fraction of the between year variance accounted for by the NA $\left(\delta+\alpha_{N A}\right)$ and SE $\left(\delta+\alpha_{S E}\right)$ synchronous components, respectively. They provide an index of synchrony within each CSG. 


\subsubsection{Testing the influence of environmental covariates in different space-time domains along}

the migration routes

The model was used to investigate correlations between times trends in post-smolt survival and environmental covariates integrated over different space-time domains occupied by salmon along the migration routes (Fig. 2). Specially, we considered two types of domains: $(i)$ domains visited during the early post-smolt phase as transit habitat specific to each SU (or to groups of geographic proximate SUs); ( $i$ i) domains visited during the late post-smolt phase that are common to all SU of the same CSG (Fig. 2 and 3).

In this section, we first describe the methods used to define the space-time domains. Then, we present the ecological hypotheses tested and the associated environmental variables integrated over those different domains. Finally, we detail the statistical method used to quantify the amount of variance of the temporal variations of post-smolts survival that is captured by the covariates in the different space-time domains.

\subsubsection{Defining specific and common CSG space-time domains}

We conducted an extensive review of the literature to define the key space-time domains occupied by post-smolts over their marine phase across the North Atlantic Ocean (Fig. 2; Sup. Mat. S2). Two types of space-time domains were defined. Specific domains are transit habitat occupied by post-smolts during their first three months at sea of migration from the estuarine and coastal areas to the common feeding area (Fig. 2, zones 1 to 9, Table S2.1, Fig S2.1). These domains are specific to each SU or to small groups of geographic proximate SU (Fig. 3 and Fig. S2.1). Common CSG domains are space-time domains corresponding to the habitat occupied by salmon in the later phase of the first year at sea (Fig. 2 domains A and B) and associated to feeding areas common to all SU within the same CSG (Fig. 3).

The only exception is for the Southwest Iceland SU, which presents different migrations from the other SU from SE CSG. Salmon from Iceland reach the sea later, in June, and do not migrate to the Norwegian Sea (Guðjónsson, Einarsson, Jónsson, \& Guðbrandsson, 2015). Consequently, for the Southwest Iceland SU, the same spatial limits are defined for the transit and common domains (Fig. 2 and Table S2.1). 


\subsubsection{Integrating environmental variables over space-time domains}

The sea surface temperature (SST) and primary production (PP) were averaged over the defined space-time domains (Fig. 3) and introduced as explanatory variables in the life cycle model to assess the extent to which the temporal variations in the post-smolt survival could be explained by environmental variations encountered in the specific or common domains occupied by salmons during the first year at sea. We also examined the influence of two large scale climate indices, the Atlantic Multidecadal Oscillation (AMO) and the North Atlantic Oscillation Index (NAOI) to assess their influence on the temporal variations in the post-smolt survival.

\section{Sea Surface Temperature (SST)}

Ocean warming is one of the major effects of climate change on marine ecosystems. An increase in seawater temperature may affect survival differently (negative or positive) through direct or indirect effects.

The direct physiological effect of an increase in temperature is difficult to predict as it can be positive or negative, depending on the range of the temperature change relative to the species' optima and tolerance. Atlantic salmon is an ectothermic species with a range of preferred temperatures at sea between $2^{\circ} \mathrm{C}$ and $14^{\circ} \mathrm{C}$ (Holm, 2000; David G. Reddin \& Schearer, 1987), with the highest post-smolt captures being realized in temperatures between $4-10^{\circ} \mathrm{C}$ (D. G. Reddin \& Friedland, 1993). Then, by directly increasing metabolism, an increase in temperature should increase growth potential of salmon, and in turn may have a positive effect on marine survival provided that foraging resources are available in sufficient quantity (Cunningham et al., 2018; Siegel, McPhee, \& Adkison, 2017). By contrast, an increase of temperature well above the optimum could have a negative effect on growth and marine survival. However, based on the literature, we rather expect negative indirect effects of an increase in seawater temperature on both growth and survival, through bottom-up control of food resources available for salmon during the first year at sea (Beaugrand \& Reid, 2012; Friedland et al., 2009; Jensen et al., 2012).

SSTs were used to calculate the seawater temperature in each space-time domain and derived from the HadISST1 datasets (See Sup. Mat. S3). Standardized anomalies of SST for each space-time domain $z$ (as defined in Table S2.1) and year $t$, denoted $S S T_{z, t}^{*}$ were calculated as: 


$$
S S T_{z, t}^{*}=\frac{\overline{S S T}_{z, t}-\overline{S S T}}{\sigma_{S S T}}
$$

where $\overline{S S T}_{z, t}$ is the SST averaged over the space-time domain $z$ (averaged over month and space) for a particular year $t, \overline{S S T}$ is the SST averaged over spatial and temporal (months) limits covered by all specific and common domains, and overall years $\mathrm{t}$, and $\sigma_{S S T}$ is the standard deviation calculated from the between year variability of the SST averaged over spatial and temporal (months) limits covered by all specific and common domains. Note that with this method, the anomalies are calculated relative to SST averaged over all space-time domains (both common and specific) and covering both NA ad SE post-smolt habitat. Therefore, the contrast in absolute value and temporal (between year) variance between the type of domains (specific versus common) and between the two CSG (NA and SE) is conserved.

\section{Primary Production (PP)}

PP was considered as indicator of the ocean production which determines the prey availability for salmon at sea and consequently expected to be positively correlated to post-smolt survival.

PP data are derived from the Earth System Model) developed by the Geophysical Fluid Dynamic Laboratory (GFDL-ESM2M, Dunne et al., 2012) (see Sup. Mat. S3 for more details).

Standardized anomalies of PP $\left(P P_{z, t}^{*}\right)$ were calculated following the same approach as SST. However, to match with the months of phytoplankton bloom, PP was integrated over the two months April-May in both specific and common domains.

\section{Atlantic Multidecadal Oscillation (AMO)}

The AMO is a low-frequency and basin-wide climate index reflecting sea surface temperature variability over the last century (Alheit, Drinkwater, \& Nye, 2014; Enfield, Mestas-Nunez, Trimble, \& others, 2001).

Previous studies have reported on a negative correlation between temporal variations of salmon abundance and the AMO in both North America (Crozon et al., 2005; K. E. Mills et al., 2013) and in Southern Europe (Beaugrand et al., 2012). Friedland et al., (2014) highlighted a differential 
response of salmon abundances from North America and Southern Europe to the AMO. Based on these publications, we expect the positive AMO to negatively impact post-smolt survival but with potentially different strength for NA and SE CSGs.

The effect of AMO on post-smolt survival is included using the average monthly value over the entire post-smolt phase (May-December); data from 1975 to 2012 were considered (see Sup. Mat. S3 for more details).

North Atlantic Oscillation Index (NAOI)

We used the winter NAOI (mean from December to March) as the NAOI is strongly associated with climatic conditions during the winter (Sup. Mat. S3). Previous studies have shown weak correlations between NAOI and salmon abundance (K. E. Mills et al., 2013; Beaugrand and Reid, 2003, 2012). Our prediction is that high winter NAOI should be associated with good feeding conditions because of positive temperature anomalies, and thus be positively correlated with postsmolt survival. However, because NAOI described different conditions in North America and Europe, our expectation is that the temporal variation of NAOI will affect the two CSGs differently.

\subsubsection{Quantifying the influence of environmental variables in the different space-time domains}

We developed a variant of the variance analysis method from Grobois et al., (2009) and LahozMonfort et al., $(2011,2013)$ to quantify the contribution of each covariate in the different spacetime domains to the temporal and spatial variations of post-smolt survival. This also allows quantifying the contribution of covariates in generating synchrony at various spatial scales.

Preliminary analysis showed that the time series of environmental variables exhibited an important level of correlation, both between variables of different nature (i.e. variations of SST, PP, AMO and NAOI are not independent) and between the different space-time domains for the same covariate. Hence, the influence of each type of covariate was considered separately, and for the same covariate, the influence in the different space-time domains at different scales was also considered separately. 
Time series of environmental covariates $\left(X_{k_{t}}\right)$, defined at different spatial scales $k$ (specific or common CSG domains) were considered as an additional factor in model M1:

$$
\text { (11) } \operatorname{logit}\left(\theta_{t, r}\right)=\beta_{r}+\delta_{t}+\alpha_{g_{t}}+\varepsilon_{t, r}+\gamma_{k} \times X_{k_{t}}
$$

where $k$ refers to the specific or common domains, and $\gamma_{k}$ is the coefficient describing the influence of covariate $X_{k}$ on post-smolt survival (two separate models were built for the two spatial scales). The $\gamma_{k}$ were drawn a priori in a non-informative Uniform prior distribution.

For covariates SST and PP at the scale of specific domains, different coefficients $\gamma_{r}$ for each SU were considered. When covariates are considered at the scale of a common CSG domain, two coefficients $\gamma_{N A}$ and $\gamma_{S E}$ were considered for the influence on NA and SE, respectively. Because our expectation is that the effects of AMO and NAOI could be different between the two CSGs, two coefficients $\gamma_{N A}$ and $\gamma_{S E}$ were considered for the influence on NA and SE, respectively. Table 2 sums up the hypotheses tested and associated model configurations that included environmental covariates.

\section{Contribution of the covariates to the temporal variability of post-smolt survival}

For each covariate considered independently, models were run with (Cov) and without the effects of covariates ( $\mathrm{NoCov}$, all $\gamma$ fixed to 0 , equivalent to model M1). For each time series of $\operatorname{logit}\left(\theta_{t, r}\right)$ , the percentage of between year variance captured by covariate can therefore be estimated by the ratio $C_{r}$ :

(12) $\quad C_{r}=1-\frac{\operatorname{Var}_{\text {tot }_{r}}(\mathrm{Cov})}{\operatorname{Var}_{\text {tot }_{r}}(\mathrm{NoCov})}$

where $\operatorname{Var}_{\text {tot }_{r}}($ noCov $)$ corresponds to the total inter-annual variance for the model without covariates as defined in eq. (3), and $\operatorname{Var}_{\text {tot }_{r}}(\mathrm{Cov})$ is the total inter-annual variance in the model with covariates (i.e., the residual variance not captured by the covariate). The average percentage of variance captured by a given covariate (denoted $C_{T O T}$ ) is then calculated over all $\mathrm{SU}$ or over 
SU within each CSG. A high value of $C_{T O T}$ corresponds to a high contribution of the covariates in the trends of post-smolt survival.

Contribution of environmental covariates to generate synchrony or asynchrony in postsmolt survival

To quantify the contribution of environmental covariates in generating synchrony or asynchrony in survival, we also assessed the amount of variance captured by the covariates at different levels of the spatial hierarchy:

$$
\begin{aligned}
& \Delta_{\delta}=1-\frac{\sigma_{\delta}^{2}(\mathrm{Cov})}{\sigma_{\delta}^{2}(\mathrm{NoCov})} \\
& \Delta_{\alpha_{g}}=1-\frac{\sigma^{2}(\mathrm{Cov})+\sigma_{\alpha_{g}}^{2}(\mathrm{Cov})}{\sigma_{\delta}^{2}(\mathrm{NoCov})+\sigma_{\alpha_{g}}^{2}(\mathrm{NoCOv})}, \text { for } g=N A \text { or } S E \\
& \Delta_{\varepsilon_{r}}=1-\frac{\sigma_{\varepsilon_{r}}^{2}(\mathrm{Cov})}{\sigma_{\varepsilon_{r}}^{2}(\mathrm{NoCov})}, \text { for } r=1, \ldots, 13
\end{aligned}
$$

$\Delta_{\delta}, \Delta_{\alpha_{g}}$, and $\Delta_{\varepsilon_{r}}$ quantify the contribution of environmental covariates to the between year variance at the global scale (general synchronous component), CSG-scale (synchronous component within a CSG) or local scale (asynchronous component), respectively. $\Delta_{\delta}$ and $\Delta_{g}$ are positive if the covariate acts as a synchronizing factor. Indeed, if the covariate captures part of the synchronous signal in components $\delta$ or $\alpha$, the variance of the synchronous random terms in the model should be lower when considering covariates (Table 2). Inversely, if $\Delta_{\varepsilon_{r}}$ is positive, the variance of asynchronous terms is greater when considering covariates, meaning that the covariate acts as an asynchronous agent (Table 2). 


\subsection{MCMC simulations and model checking}

Bayesian posterior distributions were approximated using Monte Carlo Markov Chain (MCMC) methods using Nimble (https://r-nimble.org) (de Valpine et al., 2017). The Nimble code for our model is available on GitHub: https://github.com/MaxOlmos/SALMOGLOB-Life-Cycle-Model. Two independent MCMC chains with dispersed initialization values were used. The level of autocorrelation of MCMC chains is very high (still significant at lag 30). The first $10^{6}$ iterations were used as a burn-in period. To reduce the autocorrelation in the MCMC sample used for final inferences, one out of 30 iterations post burn-in was kept and the resulting sample of 30,000 iterations per chain was used to characterize the posterior distribution. Convergence was assessed using the Gelman-Rubin statistic (Brooks \& Gelman, 1998) as implemented in the R Coda package (gelman.diag()).

Following the methodology developed in Olmos et al. (2019), the model fit to each data source was assessed by checking that the $90 \%$ credibility envelope of the posterior predictive distribution of each variable contained the observation. In addition, Bayesian p-values calculated from chisquare discrepancy tests (Gelman et al., 2014a) were calculated to check the ability of the model to replicate a posteriori data similar to those observed. The likelihood and the core structure of the population dynamic is the same as in Olmos et al. (2019), and changes in the latent model structure do not affect the way the model fits the data. As in Olmos et al. (2019), posterior predictive distributions show that the model fits well to all observations, and posterior predictive checks do not indicate strong inconsistencies between the model a posteriori and the data. Those results are not developed further in this paper (see Olmos et al. (2019) for more details).

\subsection{Model comparisons}

We compared the parsimony of models using the W-AIC criterion. The WAIC is appropriate to compare hierarchical models of any structure fitted to the same data sets (Gelman, 2014a; Hooten \& Hobbs, 2015; Watanabe, 2013). It can be considered as a generalization of the Deviance Information Criterion (Gelman, 2014a; Vehtari, Gelman, \& Gabry, 2017) and has the advantage of being directly related to the posterior predictive ability of the model. Using the common 
convention for information criteria on the deviance scale, differences of W-AIC between models can be roughly interpreted according to the following rules of thumb: a difference of 1-2 units offers little to no support in favor of a particular model; a difference of between 4 and 7 units offers considerable support for the model with the lowest W-AIC; and a difference of $>10$ units offers full support for the model with the lowest W-AIC (Burnham and Anderson, 2002; Gelman et al. 2014a; Gelman et al. 2014b).

\section{RESULTS}

\subsection{Quantifying spatial synchrony at a hierarchy of spatial scales}

\subsubsection{Model evaluation}

Model M1, which explicitly partitions the signal into a common trend plus two separate trends for each CSG, appears to be the best descriptor of the spatial coherence between SU and was therefore retained in the subsequent analyses (Supp. Mat. S1).

\subsubsection{Spatial synchrony in post-smolt survival}

Results show a strong synchrony in the temporal variations of post-smolt marine survival between all SU, but with a higher coherence within CSG (Fig. 4). The average $\overline{I C C}_{\delta}$ relative to the global scale component across all SU is $37 \%$, indicating a strong synchrony between all time series of survival and the common trends. Time series of post-smolt survival show a consistent decline across the $13 \mathrm{SU}$ over the study period. The global scale component exhibits a decrease in survival by a factor 1.8 (natural scale, not shown) with a strong drop in 1987, followed by a slight increase in the early 2000s, before slightly declining again until 2012 (Fig. 4a). The degree of synchrony with the common trend is variable depending on the SU. ICC $\delta_{\delta_{r}}$ are higher for SU within the SE CSG (Fig. 4b; average value of $I C C_{\delta_{r}}$ across all $\mathrm{SU}$ in $\mathrm{SE}=45 \%$ ) than within the NA CSG 
(average value of $I C C_{\delta_{r}}$ across all $\mathrm{SU}$ in $\mathrm{NA}=24 \%$ ), indicating that the $\mathrm{SU}$ in the $\mathrm{SE} \mathrm{CSG}$ are more strongly correlated with the global scale component than the SU in the NA CSG.

Temporal variation in post-smolt marine survival within each CSG shows a stronger coherence than among SU of the two CSGs, especially as the NA CSG presents a higher synchrony $\left(\overline{I C C}_{N A}\right.$ $=60 \%)($ Fig. $4 \mathrm{~d})$ than the SE CSG $\left(\overline{I C C}_{S E}=42 \%\right)($ Fig, $4 \mathrm{f})$. Common CSG trends (calculated as $\left.\left(\delta_{t}+\alpha_{g_{t}}\right)\right)$ revealed differences between NA and SE CSG (Fig. 4c and 4e), however, both exhibit an overall declining trend, characterized by a sharp decline in the 1990s. The survival in the NA component decreases over years with a strong decline by a factor 3 (natural scale, not shown) during 1985 to 1995 (Fig. 4c) while SE shows a smaller decline by a factor 1.9. The survival in the SE component also slightly increases between 2002 and 2007 although it remains relatively stable in the NA component after the decline of the 1990s.

Within NA, Quebec $\left(I C C_{g_{r}}=98 \%\right)$, Labrador $\left(I C C_{g_{r}}=70 \%\right)$ and Newfoundland $\left(I C C_{g_{r}}=65 \%\right)$ are the SU that are the most strongly correlated with the global trend for NA (Fig. 4d). Within SE, the strongest correlation between $\mathrm{SU}$ and the common trend is obtained for England \& Wales $\left(I C C_{g_{r}}\right.$ $=98 \%)$, Eastern $\left(I C C_{g_{r}}=58 \%\right)$ and Western Scotland $\left(I C C_{g_{r}}=55 \%\right)$ (Fig. 4f). Some SU like US in NA or N-Ireland in SE have specific trends that contrast with the average CSG trend. Logically they show weaker ICC indices $\left(I C C_{g_{r}}=30 \%\right.$ for US; $I C C_{g_{r}}=18 \%$ for N-Ireland). N-Ireland exhibited a higher inter-annual variability compared to the SE common component (Fig. 4e). US presents a stronger decline than the NA component (Fig. 4c).

This article is protected by copyright. All rights reserved 


\subsection{Influence of environmental covariates in different space-time domains along the migration routes}

\subsubsection{Time series of covariates in the different space-time domains}

Time series of anomalies of covariates SST and PP exhibit some temporal variations over the period considered (Fig. 5).

SST anomalies are in the same range between the specific and the common domains (Fig 5a and 5b). Time series of SST exhibit an overall increase over the period. Inter-annual variance of SST anomalies is generally higher in the specific than in the common CSG domains. In NA, the increase in SST is higher in the common CSG domains than in the specific ones (Fig. 5a). In SE, the drop of SST observed in the common CSG domain at the beginning of the 1990's is stronger than in the specific domains (Fig. 5b). In NA, the time series of SST in the different space-time domains show large temporal fluctuations, all marked by a strong increase starting at the beginning of the 1990s, and again after 2003, following a decline between 1998 and 2003 (Fig. 5a). The time series of SST for the SE CSG show different signals than in NA, marked by a drop of SST between 1992 and 1995, and temperatures that have decreased since 2009 (Fig. 5b).

Trends in time series of PP are weaker than for SST and slightly decreasing (Fig. 5a to 5d). The decline of PP is slightly stronger in NA than in SE. By contrast with SST, PP anomalies calculated in the specific domains are much higher than in the common CSG domains.

AMO shows a multidecadal variability and a marked increase over the time-series, especially since the beginning of the 1990's (Fig. 5e). NAOI exhibits strong inter-annual variability, with a general decline after 1990 and with considerable negative anomalies in 1996 and 2010 (Fig. 5f).

This article is protected by copyright. All rights reserved 


\subsubsection{Model comparisons}

Difference in W-AIC between model M1 and models with effects of covariates are weak and do not allow us to select one particular model (Table S4.1). Model comparisons show that the temporal variations of environmental covariates experienced by post-smolts in the common CSG domains better explain the variance in post-smolt survivals than environmental covariates in the specific space-time domains. The models considering a different effect of AMO and NAOI for each CSG are supported by the data and present low W-AIC values, similar to the ones of environmental covariates defined in the common CSG domains.

\subsubsection{Influence of PP and SST in the specific space-time domains}

Overall, temporal variations of SST and PP in the specific space-time domains occupied by postsmolts during the first three months of marine migration only explain a low part of the temporal variance of marine survival and the sign of their influence is not consistent across SU.

The absolute values of regression coefficients of SST and PP anomalies strongly differ (Fig. 6a and $6 \mathrm{~b}$ ). However, no conclusions can be drawn from those differences as the method used to calculate anomalies, anomalies of PP and SST in the specific time-space domains are not centered on 0 and do not have the same variance. Still, the sign of regression coefficient and the amount of variance explained by both covariates can be compared.

Overall, the signs of the coefficient of correlations between post-smolt marine survival and SST and PP anomalies considered in specific domains do not indicate a consistent direction of the effect across SUs. The 95\% posterior credibility intervals for most coefficients include zero, suggesting a limited influence of the variations in PP or SST in specific space-time domains on the marine survival rate. However, some exceptions are observed. In SE CSG, temporal variation of the marine survival in Ireland, Northern Ireland, Eastern Scotland, and England and Wales are negatively correlated with those of SST. In average, the SST coefficients associated with the northernmost SU of both CSGs (e.g. Southwest Iceland and Labrador to a lesser extend) are positive, whereas the majority of those associated with the southernmost SU are negative (e.g. Scotia-Fundy, US, Ireland, Northern Ireland, England and Wales, Eastern Scotland). This result suggests that the effect of SST could be different depending on the latitude, with a positive effect 
of increasing SST for SU in the northernmost post-smolt habitats, and a negative effect on SU with the southernmost post-smolt habitats. On average, PP and SST integrated over the specific space-time domains only captured a small percentage of the total variance, with SST being slightly more influential than PP $\left(C_{T O T}=0.2 \%\right.$ and $11 \%$ for PP and SST, respectively $)$ of the temporal variations of marine survival in each SU (red bars Fig. $6 \mathrm{~g}$ and $6 \mathrm{~h}$ ).

Both covariates integrated over the specific domains act mainly as asynchronizing agents, meaning that the covariates capture part of the variance of the asynchronous component of the survival rate but not of the common trends. PP contributes only to the asynchronous component (Fig. 6g, orange bars). SST also essentially contributes to the asynchronous components, although some part of the synchronous components is explained by temporal variation of SST in the specific domains. SST in the specific space-time domains explains $33 \%$ of the variance of the global component (blue bars, $\Delta_{\delta}$; Fig. $6 \mathrm{~h}$ ), $29 \%$ of the variance of the SE CSG component (green bars, $\Delta_{\alpha_{S E}}$; Fig. $6 \mathrm{~h}$ ), but $0 \%$ of the variance of the NA CSG component (green bars, $\Delta_{\alpha_{N A}}$; Fig. 6h). The local (asynchronous) influence of PP is highest for Newfoundland $\left(\Delta_{\varepsilon_{N F D L}}=22 \%\right)$, France ( $\left.\Delta_{\varepsilon_{F R}}=12 \%\right)$, Scotia-Fundy $\left(\Delta_{\varepsilon_{S F}}=10 \%\right)$, and explains less than $10 \%$ for the Gulf, US, Quebec, Ireland, Eastern Scotland, and Northern Ireland (Fig. 6g). The effect of SST is highest for South West Iceland $\left(\Delta_{\varepsilon_{S W . I C}}=86 \%\right)$, England and Wales $\left(\Delta_{\varepsilon_{E W}}=25 \%\right)$, and France $\left(\Delta_{\varepsilon_{F R}}=19 \%\right)$, but explains only a low proportion of the specific variance for the other SU (Fig. 6h). 


\subsubsection{Influence of environmental PP and SST in the common CSG domains}

SST and PP integrated over space-domains shared by all SU within the same CSG later in the first year at sea explain a larger proportion of the temporal variation of marine survival than variables integrated in specific space-time domains. Also, the signs of the coefficients of correlation between marine survival and variables indicate a consistent direction of the effect across SU.

The regression coefficients associated with PP integrated over common CSG domains for NA and SE are positive (Fig. 6c), whereas they are negative for SST (Fig. 6d). The coefficients associated with the two covariates are stronger for NA than for SE; the $95 \%$ credible intervals do not include zero for SST in NA and SE CSG and for PP in NA CSG, and 75\% credible interval do not include zero for PP in SE CSG. Temporal variations of SST capture a greater proportion of the variance ( $\left.C_{T O T} 16 \%\right)$ of the marine survival than does PP $\left(C_{T O T} 10 \%\right)$ (Fig. $6 \mathrm{j}$ and Fig. 6i, respectively).

SST and PP integrated over common CSG domains act as synchronizing agents for the temporal variability of post-smolt marine survival. SST accounts for $42 \%$ of the variance of the global trend (blue bar, $\Delta_{\delta}$; Fig. 6.j), and PP about $19 \%$ (blue bar, $\Delta_{\delta}$; Fig. 6i). When downscaling at the scale of CSG trends $(\delta+\alpha)$, SST integrated over the common CSG domains accounts for $26 \%$ and $21 \%$ of between year variance of the common trends for NA and SE, respectively (green bars, $\Delta_{\alpha_{N A}}$ and $\Delta_{\alpha_{S E}}$; Fig. 6j). PP accounts for $24 \%$ and $12 \%$ of between year variance of the common trends for NA and SE respectively (green bars, $\Delta_{\alpha_{N A}}$ and $\Delta_{\alpha_{S E}}$; Fig. 6i).

\subsubsection{Influence of large scale environmental indices: AMO and NAOI}

The AMO is negatively correlated with the trends in post-smolt survivals (Fig. 6e), but the magnitude of the effect is higher for NA than for SE. The AMO index captures a high average amount of variance $\left(C_{\text {TOT }}=13 \%\right.$, red bar; Fig. $\left.6 \mathrm{k}\right)$ and acts as a synchronizing agent of post-smolt survival. The effect of AMO accounts for $29 \%\left(\Delta_{\delta}\right), 26 \%\left(\Delta_{\alpha_{N A}}\right)$ and $21 \%\left(\Delta_{\alpha_{S E}}\right)$ of the globalscale, the NA CSG-scale, and the SE CSG scale, respectively and does not account for a specific scale component, except for England and Wales $\left(\Delta_{\varepsilon_{E W}}=14 \%\right)$ (Fig. 6k).

This article is protected by copyright. All rights reserved 
The NAO index is not correlated to post-smolt survival (Fig. 6f) and captures an insignificant part of the variance at any spatial scale (Fig. 61).

\section{DISCUSSION}

Understanding the demographic and ecological mechanisms shaping the response of populations to climate change is a prerequisite for a science-based management and conservation ecology (Koenig, 1999). A particularly challenging issue is to separate out the effects of factors acting at various stages and spatial scales. This paper addressed this issue with the Atlantic salmon as a case study. We elaborate on a hierarchical life cycle model developed by Olmos et al. (2019) to analyze the dynamics of 13 large groups of populations that sequentially occupy different habitats in the North Atlantic Ocean, with different populations occupying distinct habitats during the first period of the marine phase and sharing common habitats later on. The analyses provide a new quantification of the spatial synchrony in post-smolt marine survival examined at a hierarchy of spatial scales, from a basin scale (North Atlantic) to more local (national or regional) scales, and quantifies the amount of temporal variation in the post smolt survival that is captured by environmental changes at these spatial scales. To this end, we integrated explicit hypotheses on migration routes to test how spatial and temporal variations in the marine environment shape the covariation in post-smolt survival rate.

\subsection{Geography of covariation of post-smolt marine survival}

We partitioned the temporal variations of marine survival for $13 \mathrm{SU}$ into three components that capture (i) coherence of the signal between all SU (global scale), (ii) within each CSG (NA or SE), and (iii) for each SU specifically (asynchronous components).

Consistent with results of Olmos et al. (2019), we found strong coherence in the temporal variation of post-smolt marine survival among the $13 \mathrm{SU}$ of NA and SE, characterized by a decline in the common trend for the 13 SU over the 1971-2014 time series. 
Results also highlight an increased coherence in temporal variation of post-smolt survival at finer spatial scales. Synchronized dynamics are stronger among SU within the same CSG than between SU of different CSGs. The common trends at the scale of NA and SE capture $60 \%$ and $42 \%$ of the total variance of the temporal variations, respectively, with the remaining part of the variability being explained by local SU variations. Within the same CSG, synchrony is higher for geographically proximate SU, most likely explained by the similarity in post-smolt habitat and migration routes at sea. Specifically, in the NA CSG, Labrador, Newfoundland and Quebec are closer to the common feeding grounds in the Labrador Sea and Grand Banks. Fish of those SU are likely to have similar migration routes during the first year at sea, which would therefore explain the strong coherence in temporal variations of marine survival. Similarly, in SE, post-smolt survival rates of SU with closed migration routes to the common feeding grounds in the Norwegian Sea, such as Eastern Scotland, Western Scotland and England and Wales (the most abundant salmon rivers, the Tyne, Dee and Lune, are in the North of England) are correlated.

\subsection{Influence of environment variables in space-time domains along the migration routes}

The geographic pattern of covariation in post-smolt survival suggests a response to spatially correlated environmental drivers (Moran effect; Liebhold et al., 2004; Stenseth, 2002; Walter et al., 2017). When arriving at sea, fish occupy different habitats sequentially along their migration routes and at varying levels of population aggregation. We tested if the spatial patterns of synchronicity in marine survival rate can be explained by temporal variations of environmental conditions (SST and PP) encountered by the fish in those different habitats.

To support this, we developed an extensive review of the available information on migration timing and migration routes from the mouth of the estuary in spring to the first over-wintering stage at the end of the following autumn. Based on this review, we defined two types of spacetime domains: $(i)$ associated with the early phase of the marine life (first two months after the smolts migration); (ii) associated with the later phase of the first year at sea and corresponding to common areas where salmon of different origins mixed to feed. 
Results support the hypothesis of synchronous variations of post-smolt survival driven by environmental factors affecting salmon in the feeding grounds where multiple populations from a same CSG forage together in late summer/early autumn, in the Labrador Sea/Grand Banks for NA CSG and the Norwegian Sea for SE CSG. Temporal variations of the post-smolt marine survival are best explained by temporal variations of SST (negative correlations) and PP (positive correlations) in those space-time domains than in the specific ones.

Our results are not fully consistent with Friedland et al. (2014) who found that warm temperatures in early spring negatively affected the recruitment index in NA, whereas recruitment in SE was negatively correlated with warmer SST in late summer. However, our inferences are based on a model that considers the population dynamics of all $13 \mathrm{SU}$ in the North Atlantic Ocean in a single unified modelling framework. By contrast, data limitation and insufficient spatial coverage in Friedland et al. (2014) may have hampered their investigation of the spatial synchrony in a hierarchy of spatial scales. The authors compared proxies of marine productivity for NA and SE based on heterogeneous data sources between areas (global catch index for NA CSG and an index of marine survival based on tag returns from the North Esk River (UK) for SE CSG) and their correlative approach was not based on explicit hypotheses about salmon migration routes. Hence the lack of correlation between spring SST and marine productivity for SE CSG may come from a mismatch between the habitat occupied by salmon and the space-time domains where SST was considered.

Although previous papers reported some weak degree of association between NAOI and Atlantic salmon dynamics (Beaugrand \& Reid, 2012; K. E. Mills et al., 2013), no relationship between winter NAOI and post-smolt survival was found in the present study. One reason might be that the relationship between NAOI and salmon is not homogeneous between the two sides of the North Atlantic Ocean, and even across a latitudinal gradient within a given CSG. For instance, strong positive phases of the NAOI are associated with below-normal temperatures in SE and in the North of the Labrador region, but with above-normal temperature in Northern Europe and in the eastern coast of North America (Hurrell, Kushnir, Ottersen, \& Visbeck, 2003): the effect of NAOI on salmon may therefore not be uniform across SUs or CSGs.

This article is protected by copyright. All rights reserved 


\subsection{Indirect growth-dependent mechanisms are likely involved}

Thermal conditions encountered by salmon in their open ocean feeding grounds are likely to influence salmon survival. However, it is still unclear if salmon are influenced by direct effects of warming (by increasing energy expenditure and metabolism), or by indirect effects such as suboptimal food availability, predation, or migration timing.

The direct effect of SST warming appears less likely responsible for the observed patterns. Ectothermic animals such as salmon have both their metabolic demand and growth potential increasing with temperature (Siegel et al., 2017). Growth variations during the post-smolt phase were hypothesized as being important for survival (Friedland et al., 2008, 2014; McCarthy et al., 2008). As SST indices in the open ocean feeding grounds remained within the optimal range (between $7^{\circ} \mathrm{C}-10,5^{\circ} \mathrm{C}$ ) of Atlantic salmon (Holm, 2000; Reddin and Schearer, 1987), the observed SST warming over the time period studied is not likely to have a direct effect on marine survival, which is contrary to negative regression coefficients as well as the overall declining pattern of marine survival.

The negative correlation between the temporal variation of SST, and the positive correlation of PP with the common trends of marine survival rate rather suggest an indirect effect of SST warming acting through bottom-up trophic mechanisms. The Norwegian Sea and the Labrador Sea/Grand Banks, which are major feeding grounds for SE and NA CSG populations, are sensitive areas to climate change in the North Atlantic (Beaugrand et al., 2008). Our findings are consistent with a major trophic shift in the North Atlantic documented in the early 1990s, with reported changes across trophic levels from phytoplankton communities to seabird populations (Beaugrand et al., 2008; Beaugrand, Luczak, \& Edwards, 2009; Durant et al., 2003). Subsequent reduction of the abundance and the energetic quality of prey may have altered salmon growth at sea (K. E. Mills et al., 2013; Otero et al., 2012; Renkawitz et al., 2015) and consequently survival through sizedependent mortality (Friedland \& Reddin, 2000; Gislason et al., 2010; Peyronnet et al., 2007). Antagonistic effects of direct and indirect mechanisms may also act in synergy. Indeed, although warmer temperature may imply a higher and faster growth potential, sustaining higher metabolic rates also requires higher food availability. Therefore, under limited resource conditions, warmer temperatures may well lead to a decrease in growth (and then of survival) because energetic demand might outweigh energy intake (Daly \& Brodeur, 2015; Siegel et al., 2017). 
Another possible indirect negative effect of warmer temperature could be increasing metabolic costs and mortality through reduced concentrations of dissolved oxygen. Deutsch et al. (2015) highlighted that the combined effect of dissolved oxygen loss and warming would reduce the metabolic index (ratio of $\mathrm{O}_{2}$ supply to an organism's resting $\mathrm{O}_{2}$ demand) through the upper water column ( 0 to $400 \mathrm{~m}$ ) by $\sim 20 \%$ globally and by $\sim 50 \%$ in mid-latitude Northern Hemisphere oceans. Investigating the combined effect of temperature warming and oxygen loss on Atlantic salmon habitat would be worth considering in the future.

\subsection{Local specificities in temporal variations}

Beyond the general patterns, our results reveal some differences in the temporal variations of postsmolt survival and response to environmental variations between CSG and between SU. Some of these can be explained by local specificities but are mostly the consequences of complex yet unexplained mechanisms.

Results revealed a higher decline in post-smolt survival, a stronger coherence between SU and a stronger effect of PP and SST in North America than in Southern Europe. This might result from the particularly fast warming of the ocean in the Northwest Atlantic, especially in the Labrador Sea/Grand Banks (Belkin, 2009; A. Pershing, Dayton, Franklin, \& Kennedy, 2018; Taboada \& Anadón, 2012). Additionally, weaker synchrony observed in SE may be explained by the diversity of marine environments and associated growth conditions encountered during the post-smolt migration leading to the feeding areas in the Norwegian Sea. Post-smolt diet reported by Haugland et al. (2006) shows high spatial and temporal variability in terms of prey composition, with diet dominated by blue whiting in the Shelf Edge Current in the west of the United Kingdom, and by sandeel and herring in the North Sea and the Norwegian Sea. Such a high portfolio of potential prey depending on the area may reduce the synchronizing effect of environmental fluctuations.

The sign of the correlations between post-smolt survival and SST integrated over the specific time-space domains occupied by salmon during the first three months of marine migration are not consistent across SUs. Specifically, a negative correlation between post-smolt survival of ScotiaFundy, US, Ireland, Northern Ireland and England and Wales and SST integrated over specific domains may result from particularly warm temperatures in those space-time domains. In 
particular, SST in the Gulf of Maine has increased faster than $99 \%$ of the global ocean (A. J. Pershing et al., 2015), which could explain why US and Scotia-Fundy SU present the strongest declines in post-smolt survivals.

A negative correlation between PP integrated over the specific space-time domains and survival in the Labrador and Newfoundland and France SU was not expected. Salmon from the Labrador and Newfoundland SU have a shorter migration to the common feeding grounds (Bley \& Moring, 1988; Friedland, 1994) and may directly migrate to the common domains to feed. The spatial resolution of the specific space-time domain defined for the France SU, that encompasses the Biscay Bay, the North Sea and the Western coast of UK, could be too large. Populations from the North (Brittany and Normandy) and from South West of France may have different migration routes. Mixing different ecosystems with different possible trophic dynamics may have blurred the signal (Jensen et al., 2012; Haugland et al., 2006).

\subsection{Limits and future prospects}

In this study, we only considered a limited set of environmental covariates, namely SST, PP, and large-scale climate proxies, AMO and winter NAOI. The limited set of tested variables result from a trade-off between hypothesis testing about the mechanisms that drive post-smolt survival and the availability of data over the required spatial and temporal scales.

Extending the approach to the Northern Europe (NE) SU would also allow extending the gradient of environmental variation and may contribute to an even better understanding of the response of Atlantic salmon populations to large scale ecosystem changes. Stock assessment data for NE SU is only available for a shorter time series (starting in 1995 only; ICES, 2015). Nevertheless, it is characterized by a general decline in productivity over the period, suggesting a likely synchrony among the three CSG over the North Atlantic. Incorporating this data into the model would allow for extending the modelling framework to all SU in the North Atlantic.

Because of data limitations, the model structure forces all temporal variations in survival to occur between the smolt migration and the Pre-Fishery stage. Indeed, as already discussed by MassiotGranier et al. (2015) and Olmos et al. (2019), the data currently available do not allow partitioning out the temporal variations of the marine mortality that occur at different periods of the marine 
phase. To better understand the effect of environmental variations on marine survival, more data would be needed to partition out the natural morality along the migration routes.

We also assumed that the space-time domains sequentially occupied by salmon during the first year at sea have not changed over the 1971 to 2014 period. However, both the timing of smolt migration (Otero et al., 2012; Satterthwaite et al., 2014), and the boundaries of favorable habitat at sea (Cheung et al., 2009; Poloczanska et al., 2013) have changed which may have altered salmon migration routes (Guðjónsson et al. 2015). In addition, spring plankton blooms and therefore the peak of higher trophic resources available for salmon may be advanced in the season and may occur in different places (Edwards et al., 2010; Malick, Cox, Mueter, Peterman, \& Bradford, 2015; Parmesan \& Yohe, 2003), thus potentially creating a mismatch between salmon migration and available resources (Cushing, 1990).

Last, our findings have direct management implications. Indeed, post-smolt marine survival is one of the main factors controlling Atlantic salmon stock productivity. Accurately accounting for and forecasting temporal variation in the post-smolt marine survival will provide for a more robust stock assessment and the provision of multi-year catch advice for the mixed-stock fisheries occurring on these SUs within the North Atlantic (ICES, 2019; Vert-pre et al. 2013; Britten et al. 2016). Also, developing models that account for the effect of environmental covariates on forecasting is critical to be able to integrate climate predictions scenarios in those forecasts. In this perspective, building models that appropriately consider how environmental changes can impact groups of populations simultaneously or differently is therefore critical to develop appropriate management measures at various spatial scales.

\section{Acknowledgements}

The research leading to these results has received funding from the Agence Française de la Biodiversité under grant agreement INRA-AFB SalmoGlob 2016-2018. The study was partfunded by the European Regional Development Fund through the Interreg Channel VA Programme, Project SAMARCH Salmonid Management Round the Channel. 


\section{References}

Aas, $\emptyset$., Einum, S., Klemetsen, A., \& Skurdal, J. (2010). Atlantic salmon ecology. In Atlantic Salmon Ecology (pp. i-xxviii). Retrieved from

http://doi.wiley.com/10.1002/9781444327755.fmatter

Alheit, J., Drinkwater, K. F., \& Nye, J. A. (2014). Introduction to Special Issue: Atlantic

Multidecadal Oscillation-mechanism and impact on marine ecosystems. Journal of Marine Systems, 133, 1-3. https://doi.org/10.1016/j.jmarsys.2013.11.012

Beaugrand, G., Edwards, M., Brander, K., Luczak, C., \& Ibanez, F. (2008). Causes and projections of abrupt climate-driven ecosystem shifts in the North Atlantic: Causes and projections of abrupt climate-driven ecosystem shifts. Ecology Letters, 11(11), 1157-1168. https://doi.org/10.1111/j.1461-0248.2008.01218.x

Beaugrand, G., Luczak, C., \& Edwards, M. (2009). Rapid biogeographical plankton shifts in the North Atlantic Ocean. Global Change Biology, 15(7), 1790-1803.

https://doi.org/10.1111/j.1365-2486.2009.01848.x

Beaugrand, G., \& Reid, P. C. (2012). Relationships between North Atlantic salmon, plankton, and hydroclimatic change in the Northeast Atlantic. ICES Journal of Marine Science: Journal Du Conseil, 69(9), 1549-1562. https://doi.org/10.1093/icesjms/fss153

Belkin, I. M. (2009). Rapid warming of Large Marine Ecosystems. Progress in Oceanography, 81(1-4), 207-213. https://doi.org/10.1016/j.pocean.2009.04.011

Bley, P. W., \& Moring, J. R. (1988). Freshwater and ocean survival of Atlantic salmon and steelhead: A synopsis. 88.

Britten, G. L., Dowd, M., \& Worm, B. (2016). Changing recruitment capacity in global fish stocks. Proceedings of the National Academy of Sciences, 113(1), 134-139. https://doi.org/10.1073/pnas.1504709112

Brooks, S. P., \& Gelman, A. (1998). General Methods for Monitoring Convergence of Iterative Simulations. Journal of Computational and Graphical Statistics, 7(4), 434-455. https://doi.org/10.1080/10618600.1998.10474787 
Brown, C. J., Schoeman, D. S., Sydeman, W. J., Brander, K., Buckley, L. B., Burrows, M., ... Richardson, A. J. (2011). Quantitative approaches in climate change ecology. Global Change Biology, 17(12), 3697-3713. https://doi.org/10.1111/j.1365-2486.2011.02531.x

Buckland, S. T., Newman, K. B., Thomas, L., \& Koesters, N. B. (2004). State-space models for the dynamics of wild animal populations. Ecological Modelling, 171(1-2), 157-175. https://doi.org/10.1016/j.ecolmodel.2003.08.002

Burnham K.P. and Anderson, D.R. 2002. Model selection and multimodel inference. A practical theoretic information approach. Springer Verlag, 488p.

Chaput, G. (2012). Overview of the status of Atlantic salmon (Salmo salar) in the North Atlantic and trends in marine mortality. ICES Journal of Marine Science, 69(9), 1538-1548. https://doi.org/10.1093/icesjms/fss013

Chaput, G., Carr, J., Daniels, J., Tinker, S., Jonsen, I., \& Whoriskey, F. (2018). Atlantic salmon ( Salmo salar ) smolt and early post-smolt migration and survival inferred from multi-year and multi-stock acoustic telemetry studies in the Gulf of St. Lawrence, northwest Atlantic. ICES Journal of Marine Science. https://doi.org/10.1093/icesjms/fsy156

Cheung, W. W. L., Lam, V. W. Y., Sarmiento, J. L., Kearney, K., Watson, R., \& Pauly, D. (2009). Projecting global marine biodiversity impacts under climate change scenarios. Fish and Fisheries, 10(3), 235-251. https://doi.org/10.1111/j.1467-2979.2008.00315.x

Clark, J. S. (2004). Why environmental scientists are becoming Bayesians: Modelling with Bayes. Ecology Letters, 8(1), 2-14. https://doi.org/10.1111/j.1461-0248.2004.00702.x

Cressie, N., Calder, C. A., Clark, J. S., Hoef, J. M. V., \& Wikle, C. K. (2009). Accounting for uncertainty in ecological analysis: The strengths and limitations of hierarchical statistical modeling. Ecological Applications, 19(3), 553-570. https://doi.org/10.1890/07-0744.1

Cunningham, C. J., Westley, P. A. H., \& Adkison, M. D. (2018). Signals of large scale climate drivers, hatchery enhancement, and marine factors in Yukon River Chinook salmon survival revealed with a Bayesian life history model. Global Change Biology, 24(9), 43994416. https://doi.org/10.1111/gcb.14315

Cushing, D. H. (1990). Plankton Production and Year-class Strength in Fish Populations: An Update of the Match/Mismatch Hypothesis. In Advances in Marine Biology (Vol. 26, pp. 249-293). https://doi.org/10.1016/S0065-2881(08)60202-3 
Daly, E. A., \& Brodeur, R. D. (2015). Warming Ocean Conditions Relate to Increased Trophic Requirements of Threatened and Endangered Salmon. PLOS ONE, 10(12), e0144066. https://doi.org/10.1371/journal.pone.0144066

de Valpine, P., Turek, D., Paciorek, C. J., Anderson-Bergman, C., Lang, D. T., \& Bodik, R. (2017). Programming With Models: Writing Statistical Algorithms for General Model Structures With NIMBLE. Journal of Computational and Graphical Statistics, 26(2), 403-413. https://doi.org/10.1080/10618600.2016.1172487

Deutsch, C., Ferrel, A., Seibel, B., Portner, H.-O., \& Huey, R. B. (2015). Climate change tightens a metabolic constraint on marine habitats. Science, 348(6239), 1132-1135. https://doi.org/10.1126/science.aaa1605

Dunne, J. P., John, J. G., Adcroft, A. J., Griffies, S. M., Hallberg, R. W., Shevliakova, E., ... Zadeh, N. (2012). GFDL's ESM2 Global Coupled Climate-Carbon Earth System Models. Part I: Physical Formulation and Baseline Simulation Characteristics. Journal of Climate, 25(19), 6646-6665. https://doi.org/10.1175/JCLI-D-11-00560.1

Durant, J. M., Anker-Nilssen, T., \& Stenseth, N. C. (2003). Trophic interactions under climate fluctuations: The Atlantic puffin as an example. Proceedings of the Royal Society B: Biological Sciences, 270(1523), 1461-1466. https://doi.org/10.1098/rspb.2003.2397

Edwards, M., Beaugrand, G., Hays, G. C., Koslow, J. A., \& Richardson, A. J. (2010). Multi-decadal oceanic ecological datasets and their application in marine policy and management. Trends in Ecology \& Evolution, 25(10), 602-610. https://doi.org/10.1016/j.tree.2010.07.007

Elliott, J. M. (2001). The relative role of density in the stock-recruitment relationship of salmonids. Stock, Recruitment and Reference Points: Assessment and Management of Atlantic Salmon, 25-66.

Enfield, D. B., Mestas-Nunez, A. M., Trimble, P. J., \& others. (2001). The Atlantic multidecadal oscillation and its relation to rainfall and river flows in the continental U. S. Geophysical Research Letters, 28(10), 2077-2080.

Friedland, K. D. (1994). Marine survival of restoration stocks. Pp. 223-239 in a Hard Look at Some Tough Issues, S. Calabi, and A. Stout, eds. Camden, ME: Silver Quill Books. 
Friedland, K. D., Chaput, G., \& Maclean, J. (2005). The emerging role of climate in post-smolt growth of Atlantic salmon. ICES Journal of Marine Science, 62(7), 1338-1349. https://doi.org/10.1016/j.icesjms.2005.04.013

Friedland, K. D., Hansen, L. P., Dunkley, David. A., \& MacLean, J. C. (2000). Linkage between ocean climate, post-smolt growth, and survival of Atlantic salmon (Salmo salar L.) in the North Sea area. ICES Journal of Marine Science, 57(2), 419-429. https://doi.org/10.1006/jmsc.1999.0639

Friedland, K. D., MacLean, J. C., Hansen, L. P., Peyronnet, A. J., Karlsson, L., Reddin, D. G., ... McCarthy, J. L. (2008). The recruitment of Atlantic salmon in Europe. ICES Journal of Marine Science, 66(2), 289-304. https://doi.org/10.1093/icesjms/fsn210

Friedland, K. D., Moore, D., \& Hogan, F. (2009). Retrospective growth analysis of Atlantic salmon (Salmo salar) from the Miramichi River, Canada. Canadian Journal of Fisheries and Aquatic Sciences, 66(8), 1294-1308. https://doi.org/10.1139/F09-077

Friedland, K. D., Reddin, D., \& Castonguay, M. (2003). Ocean thermal conditions in the post-smolt nursery of North American Atlantic salmon. ICES Journal of Marine Science, 60(2), 343355. https://doi.org/10.1016/S1054-3139(03)00022-5

Friedland, K. D., \& Reddin, D. G. (2000). Growth patterns of Labrador Sea Atlantic salmon postsmolts and the temporal scale of recruitment synchrony for North American salmon stocks. Canadian Journal of Fisheries and Aquatic Sciences, 57(6), 1181-1189. https://doi.org/10.1139/cjfas-57-6-1181

Friedland, K. D., Shank, B. V., Todd, C. D., McGinnity, P., \& Nye, J. A. (2014). Differential response of continental stock complexes of Atlantic salmon (Salmo salar) to the Atlantic Multidecadal Oscillation. Journal of Marine Systems, 133, 77-87. https://doi.org/10.1016/j.jmarsys.2013.03.003

Gelman, A. (2014a). Bayesian data analysis (Third edition). Boca Raton: CRC Press.

Gelman A, Hwang J, Vehtari A. (2014b). Understanding predictive information criteria for Bayesian models. Statistics and Computing, 24:997-1016

Gislason, H., Daan, N., Rice, J. C., \& Pope, J. G. (2010). Size, growth, temperature and the natural mortality of marine fish: Natural mortality and size. Fish and Fisheries, 11(2), 149-158. https://doi.org/10.1111/j.1467-2979.2009.00350.x 
Grosbois, V., Harris, M. P., Anker-Nilssen, T., McCleery, R. H., Shaw, D. N., Morgan, B. J. T., \& Gimenez, O. (2009). Modeling survival at multi-population scales using mark-recapture data. Ecology, 90(10), 2922-2932. https://doi.org/10.1890/08-1657.1

Guđjónsson, S., Einarsson, S. M., Jónsson, I. R., \& Guðbrandsson, J. (2015). Marine feeding areas and vertical movements of Atlantic salmon ( Salmo salar ) as inferred from recoveries of data storage tags. Canadian Journal of Fisheries and Aquatic Sciences, 72(7), 1087-1098. https://doi.org/10.1139/cjfas-2014-0562

Harley, C. D. G., Randall Hughes, A., Hultgren, K. M., Miner, B. G., Sorte, C. J. B., Thornber, C. S., ... Williams, S. L. (2006). The impacts of climate change in coastal marine systems: Climate change in coastal marine systems. Ecology Letters, 9(2), 228-241.

https://doi.org/10.1111/j.1461-0248.2005.00871.x

Haugland, M., Holst, J., Holm, M., \& Hansen, L. (2006). Feeding of Atlantic salmon (Salmo salar L.) post-smolts in the Northeast Atlantic. ICES Journal of Marine Science, 63(8), 1488-1500. https://doi.org/10.1016/j.icesjms.2006.06.004

Heino, M. (1998). Noise Colour, Synchrony and Extinctions in Spatially Structured Populations. Oikos, 83(2), 368. https://doi.org/10.2307/3546851

Holm, M. (2000). Spatial and temporal distribution of post-smolts of Atlantic salmon (Salmo salar L.) in the Norwegian Sea and adjacent areas. ICES Journal of Marine Science, 57(4), 955964. https://doi.org/10.1006/jmsc.2000.0700

Hooten, M. B., \& Hobbs, N. T. (2015). A guide to Bayesian model selection for ecologists. Ecological Monographs, 85(1), 3-28. https://doi.org/10.1890/14-0661.1

Hurrell, J. W., Kushnir, Y., Ottersen, G., \& Visbeck, M. (2003). An overview of the North Atlantic Oscillation. In J. W. Hurrell, Y. Kushnir, G. Ottersen, \& M. Visbeck (Eds.), Geophysical Monograph Series (Vol. 134, pp. 1-35). https://doi.org/10.1029/134GM01

ICES. 2015. Report of the Working Group on North Atlantic Salmon (WGNAS), March 17-March 26, 2015, Moncton, Canada. ICES CM 2015/ACOM:09. 332p

ICES. 2017. Report of the Working Group on North Atlantic Salmon (WGNAS), 29 March-7 April 2017, Copenhagen, Denmark. ICES CM 2017/ACOM:20. 296 pp. Retrieved from http://ices.dk/sites/pub/Publication\%20Reports/Expert\%20Group\%20Report/acom/2017 /WGNAS/wgnas_2017.pdf 
ICES. 2019. Working Group on North Atlantic Salmon (WGNAS). ICES Scientific Reports. 1:16. 368 pp. http://doi.org/10.17895/ices.pub.4978

Jensen, A. J., O Maoileidigh, N., Thomas, K., Einarsson, S. M., Haugland, M., Erkinaro, J., ... Ostborg, G. M. (2012). Age and fine-scale marine growth of Atlantic salmon post-smolts in the Northeast Atlantic. ICES Journal of Marine Science, 69(9), 1668-1677. https://doi.org/10.1093/icesjms/fss086

Jonsson, N., \& Jonsson, B. (2004). Size and age of maturity of Atlantic salmon correlate with the North Atlantic Oscillation Index (NAOI). Journal of Fish Biology, 64(1), 241-247. https://doi.org/10.1111/j.1095-8649.2004.00269.x

Jonsson, N., Jonsson, B., \& Hansen, L. P. (1998). The relative role of density-dependent and density-independent survival in the life cycle of Atlantic salmon Salmo salar. Journal of Animal Ecology, 67(5), 751-762. https://doi.org/10.1046/j.1365-2656.1998.00237.x

Lahoz-Monfort, J. J., Morgan, B. J. T., Harris, M. P., Daunt, F., Wanless, S., \& Freeman, S. N. (2013). Breeding together: Modeling synchrony in productivity in a seabird community. Ecology, 94(1), 3-10. https://doi.org/10.1890/12-0500.1

Lahoz-Monfort, J. J., Morgan, B. J. T., Harris, M. P., Wanless, S., \& Freeman, S. N. (2011). A capture-recapture model for exploring multi-species synchrony in survival: Multi-species synchrony in adult survival. Methods in Ecology and Evolution, 2(1), 116-124. https://doi.org/10.1111/j.2041-210X.2010.00050.x

Liebhold, A., Koenig, W. D., \& Bjørnstad, O. N. (2004). Spatial Synchrony in Population Dynamics*. Annual Review of Ecology, Evolution, and Systematics, 35(1), 467-490. https://doi.org/10.1146/annurev.ecolsys.34.011802.132516

Malick, M. J., Cox, S. P., Mueter, F. J., Peterman, R. M., \& Bradford, M. (2015). Linking phytoplankton phenology to salmon productivity along a north?south gradient in the Northeast Pacific Ocean. Canadian Journal of Fisheries and Aquatic Sciences, 72(5), 697708. https://doi.org/10.1139/cjfas-2014-0298

McCarthy, J. L., Friedland, K. D., \& Hansen, L. P. (2008). Monthly indices of the post-smolt growth of Atlantic salmon from the Drammen River, Norway. Journal of Fish Biology, 72(7), 15721588. https://doi.org/10.1111/j.1095-8649.2008.01820.x 
Mills, D. H. (1989). Ecology and management of Atlantic salmon. London ; New York: Chapman and Hall.

Mills, K. E., Pershing, A. J., Sheehan, T. F., \& Mountain, D. (2013). Climate and ecosystem linkages explain widespread declines in North American Atlantic salmon populations. Global Change Biology, 19(10), 3046-3061. https://doi.org/10.1111/gcb.12298

Milner, N. J., Elliott, J. M., Armstrong, J. D., Gardiner, R., Welton, J. S., \& Ladle, M. (2003). The natural control of salmon and trout populations in streams. Fisheries Research, 62(2), 111-125. https://doi.org/10.1016/S0165-7836(02)00157-1

Moran, P. (1953). The statistical analysis of the Canadian Lynx cycle. Australian Journal of Zoology, 1(3), 291. https://doi.org/10.1071/ZO9530291

Myers, R. A., Mertz, G., \& Bridson, J. (1997). Spatial scales of interannual recruitment variations of marine, anadromous, and freshwater fish. Canadian Journal of Fisheries and Aquatic Sciences, 54(6), 1400-1407. https://doi.org/10.1139/f97-045

Olmos, M., Massiot-Granier, F., Prévost, E., Chaput, G., Bradbury, I. R., Nevoux, M., \& Rivot, E. (2019). Evidence for spatial coherence in time trends of marine life history traits of Atlantic salmon in the North Atlantic. Fish and Fisheries, 20(2), 322-342. https://doi.org/10.1111/faf.12345

Otero, J., Jensen, A. J., L'Abée-Lund, J. H., Stenseth, N. Chr., Storvik, G. O., \& Vøllestad, L. A. (2012). Contemporary ocean warming and freshwater conditions are related to later sea age at maturity in Atlantic salmon spawning in Norwegian rivers. Ecology and Evolution, 2(9), 2192-2203. https://doi.org/10.1002/ece3.337

Palmqvist, E., \& Lundberg, P. (1998). Population Extinctions in Correlated Environments. Oikos, 83(2), 359. https://doi.org/10.2307/3546850

Parent, E., \& Rivot, E. (2012). Introduction to hierarchical Bayesian modeling for ecological data. Boca Raton: CRC Press.

Parmesan, C., \& Yohe, G. (2003). A globally coherent fingerprint of climate change impacts across natural systems. Nature, 421(6918), 37-42. https://doi.org/10.1038/nature01286

Pershing, A., Dayton, A., Franklin, B., \& Kennedy, B. (2018). Evidence for Adaptation from the 2016 Marine Heatwave in the Northwest Atlantic Ocean. Oceanography, 31(2). https://doi.org/10.5670/oceanog.2018.213 
Pershing, A. J., Alexander, M. A., Hernandez, C. M., Kerr, L. A., Le Bris, A., Mills, K. E., ... Thomas, A. C. (2015). Slow adaptation in the face of rapid warming leads to collapse of the Gulf of Maine cod fishery. Science, 350(6262), 809-812. https://doi.org/10.1126/science.aac9819

Pershing, A. J., Head, E. H. J., Greene, C. H., \& Jossi, J. W. (2010). Pattern and scale of variability among Northwest Atlantic Shelf plankton communities. Journal of Plankton Research, 32(12), 1661-1674. https://doi.org/10.1093/plankt/fbq058

Peyronnet, A., Friedland, K. D., Maoileidigh, N. ó, Manning, M., \& Poole, W. R. (2007). Links between patterns of marine growth and survival of Atlantic salmon Salmo salar, L. Journal of Fish Biology, 71(3), 684-700. https://doi.org/10.1111/j.1095-8649.2007.01538.x

Poloczanska, E. S., Brown, C. J., Sydeman, W. J., Kiessling, W., Schoeman, D. S., Moore, P. J., ... Richardson, A. J. (2013). Global imprint of climate change on marine life. Nature Climate Change, 3(10), 919-925. https://doi.org/10.1038/nclimate1958

Post, E., \& Forchhammer, M. C. (2002). Synchronization of animal population dynamics by largescale climate. Nature, 420(6912), 168-171. https://doi.org/10.1038/nature01064

Ranta, E. (1997). The Spatial Dimension in Population Fluctuations. Science, 278(5343), 16211623. https://doi.org/10.1126/science.278.5343.1621

Reddin, D. G., \& Friedland, K. D. (1993). Marine environmental factors influencing the movement and survival of Atlantic salmon. In Salmon in the Sea and New Enhancement Strategies, pp. 79-103. Ed. By D. Mills. Fishing News Books, Blackwell, Great Britain. 424 pp.

Reddin, David G., \& Schearer, M. (1987). Sea-surface temperature and distribution of Atlantic salmon in the Northwest Atlantic Ocean. 1, 262-275. Amer. Fish. Soc. Symp.

Renkawitz, M., Sheehan, T., Dixon, H., \& Nygaard, R. (2015). Changing trophic structure and energy dynamics in the Northwest Atlantic: Implications for Atlantic salmon feeding at West Greenland. Marine Ecology Progress Series, 538, 197-211. https://doi.org/10.3354/meps11470

Rivot, E., Prévost, E., Parent, E., \& Baglinière, J. L. (2004). A Bayesian state-space modelling framework for fitting a salmon stage-structured population dynamic model to multiple time series of field data. Ecological Modelling, 179(4), 463-485. https://doi.org/10.1016/j.ecolmodel.2004.05.011 
Rochette, S., Le Pape, O., Vigneau, J., \& Rivot, E. (2013). A hierarchical Bayesian model for embedding larval drift and habitat models in integrated life cycles for exploited fish. Ecological Applications, 23(7), 1659-1676. https://doi.org/10.1890/12-0336.1

Satterthwaite, W., Carlson, S., Allen-Moran, S., Vincenzi, S., Bograd, S., \& Wells, B. (2014). Matchmismatch dynamics and the relationship between ocean-entry timing and relative ocean recoveries of Central Valley fall run Chinook salmon. Marine Ecology Progress Series, 511, 237-248. https://doi.org/10.3354/meps10934

Siegel, J. E., McPhee, M. V., \& Adkison, M. D. (2017). Evidence that Marine Temperatures Influence Growth and Maturation of Western Alaskan Chinook Salmon. Marine and Coastal Fisheries, 9(1), 441-456. https://doi.org/10.1080/19425120.2017.1353563

Soberon, J., \& Nakamura, M. (2009). Niches and distributional areas: Concepts, methods, and assumptions. Proceedings of the National Academy of Sciences, 106(Supplement_2), 19644-19650. https://doi.org/10.1073/pnas.0901637106

Stelzenmüller, V., Schulze, T., Fock, H., \& Berkenhagen, J. (2011). Integrated modelling tools to support risk-based decision-making in marine spatial management. Marine Ecology Progress Series, 441, 197-212. https://doi.org/10.3354/meps09354

Stenseth, N. Chr. (2002). Ecological Effects of Climate Fluctuations. Science, 297(5585), 12921296. https://doi.org/10.1126/science.1071281

Szuwalski, C. S., Vert-Pre, K. A., Punt, A. E., Branch, T. A., \& Hilborn, R. (2015). Examining common assumptions about recruitment: A meta-analysis of recruitment dynamics for worldwide marine fisheries. Fish and Fisheries, 16(4), 633-648. https://doi.org/10.1111/faf.12083

Taboada, F. G., \& Anadón, R. (2012). Patterns of change in sea surface temperature in the North Atlantic during the last three decades: Beyond mean trends. Climatic Change, 115(2), 419-431. https://doi.org/10.1007/s10584-012-0485-6

Vehtari, A., Gelman, A., \& Gabry, J. (2017). Practical Bayesian model evaluation using leave-oneout cross-validation and WAIC. Statistics and Computing, 27(5), 1413-1432. https://doi.org/10.1007/s11222-016-9696-4

Walter, J. A., Sheppard, L. W., Anderson, T. L., Kastens, J. H., Bjørnstad, O. N., Liebhold, A. M., \& Reuman, D. C. (2017). The geography of spatial synchrony. Ecology Letters, 20(7), 801814. https://doi.org/10.1111/ele.12782

This article is protected by copyright. All rights reserved 
Watanabe, S. (2013). A widely applicable Bayesian information criterion. Journal of Machine Learning Research, 14, 867-897.

Zimmermann, F., Claireaux, M., \& Enberg, K. (2019). Common trends in recruitment dynamics of north-east Atlantic fish stocks and their links to environment, ecology and management. Fish and Fisheries, 20(3), 518-536. https://doi.org/10.1111/faf.12360 


\section{Tables}

Table 1: Prior distributions used for the parameters of the hierarchical structures. $\mathrm{N}$ refers to a normal distribution and $\mathrm{U}$ refers to a uniform distribution.

\section{PARAMETERS}

SPATIAL COMPONENT

$r=1: 13$

Prior distribution

$g=N A, S E$

\begin{tabular}{lll}
\hline Specific Intercept & $\mu$ & $\sim N(0, \sigma=10)$ \\
& $\sigma_{\beta}$ & $\sim U(0,5)$ \\
\hline Standard deviation & $\sigma_{\varepsilon_{r}}$ & $\sim U(0,5)$ \\
Specific component & & $\sim U(0,5)$ \\
\hline Standard deviation & $\sigma_{\alpha_{g}}$ & $\sim U(0,5)$ \\
CSG-specific component & & \\
\hline Standard deviation & $\sigma_{\delta}$ & \\
Global component & & \\
\hline
\end{tabular}

This article is protected by copyright. All rights reserved 
Table 2: Summary of the hypotheses tested and the associated model configurations that included environmental covariates.

\begin{tabular}{|c|c|c|c|c|c|c|c|}
\hline $\begin{array}{c}\text { SPATIAL } \\
\text { SCALE } \\
k\end{array}$ & $\begin{array}{l}\text { TEMPORAL } \\
\text { PERIOD OF } \\
\text { THE POST- } \\
\text { SMOLT } \\
\text { PHASE }\end{array}$ & $\begin{array}{c}\text { COVARIATE } \\
x_{t}\end{array}$ & MODELS & $\begin{array}{c}\text { Covariate } \\
\text { contributes } \\
\text { to the } \\
\text { decline in } \\
\text { post-smolt- } \\
\text { survival if }\end{array}$ & $\begin{array}{l}\text { Covariate acts } \\
\qquad \text { as } \\
\text { synchronizing } \\
\text { agent at the } \\
\text { global scale if }\end{array}$ & $\begin{array}{l}\text { Covariate act } \\
\qquad \text { as } \\
\text { synchronizing } \\
\text { agent at the } \\
\text { CSG scale if }\end{array}$ & $\begin{array}{l}\text { Covariate act as } \\
\text { asynchronizing } \\
\text { agent if }\end{array}$ \\
\hline $\begin{array}{l}\text { Influence of } \\
\text { covariates in the } \\
\text { specific space- } \\
\text { time domains }\end{array}$ & $\begin{array}{l}\text { Spring of the } \\
\text { first year at sea }\end{array}$ & $\begin{array}{c}\text { PP } \\
\text { SST }\end{array}$ & $\begin{array}{c}\operatorname{logit}\left(\boldsymbol{\theta}_{t, r}\right)=\boldsymbol{\beta}_{\boldsymbol{r}}+\boldsymbol{\delta}_{\boldsymbol{t}}+\boldsymbol{\alpha}_{\boldsymbol{g}_{\boldsymbol{t}}}+\boldsymbol{\varepsilon}_{\boldsymbol{t}, \boldsymbol{r}}+\gamma_{\boldsymbol{r}} \times \boldsymbol{X}_{\boldsymbol{r}_{\boldsymbol{t}}} \\
\text { with } \gamma_{r} \sim U(-6,6) \\
r=1: 13\end{array}$ & & & & \\
\hline $\begin{array}{l}\text { Influence of the } \\
\text { covariates in the } \\
\text { common space- } \\
\text { time domains }\end{array}$ & $\begin{array}{l}\text { Late summer } \\
\text { of the first } \\
\text { year at sea } \\
\text { Large Scale } \\
\text { Indices }\end{array}$ & $\begin{array}{l}\text { PP } \\
\text { SST } \\
\text { AMO }\end{array}$ & $\begin{array}{c}\operatorname{logit}\left(\boldsymbol{\theta}_{\boldsymbol{t}, \boldsymbol{r}}\right)=\boldsymbol{\beta}_{\boldsymbol{r}}+\boldsymbol{\delta}_{\boldsymbol{t}}+\boldsymbol{\alpha}_{\boldsymbol{g}_{\boldsymbol{t}}}+\boldsymbol{\varepsilon}_{\boldsymbol{t}, \boldsymbol{r}}+\boldsymbol{\gamma}_{\boldsymbol{g}} \times \boldsymbol{X}_{\boldsymbol{g}_{\boldsymbol{t}}} \\
\text { with } \gamma_{g} \sim U(-6,6) \\
g=N A \text { or } S E\end{array}$ & & & & \\
\hline
\end{tabular}

This article is protected by copyright. All rights reserved 


\section{Legends}

Figure 1: Structure of the age- and stage-based life cycle model and covariation structure among the 13 stock units (adapted from Olmos et al. 2019). Sources of covariation include: 1) covariation in the time series of post-smolt survival and proportion maturing as 1SW (depending on the model structure M1, M2 and M3; see Table 1); 2) Covariation through fisheries operating on mixtures of SU at sea. Red boxes refer to NA SU $(I=1, \ldots, 6)$, blue boxes refer to SE SU $(j=1, \ldots, 7)$ and purple boxes refer to both NA and SE SU.

Figure 2: Location of the 13 stock units and specific and common space-time domains considered in North Atlantic. Stock units of North America: NFLD = Newfoundland, GF = Gulf, SF = Scotia-Fundy, US = USA, QB = Quebec, and LB=Labrador. Stock units in Southern Europe: IR = Ireland, E\&W = UK(England and Wales), FR = France, E.SC = UK(Eastern Scotland), W.SC = UK(Western Scotland), N.IR = UK(Northern Ireland), and SWIC= Southwest Iceland). Specific and common CSG space-time domains are in orange and green respectively. See Table S2.1 for correspondence between space-time domains and SU.

Figure 3. Theoretical representation of the hierarchy of space-time domains. Orange: Space-time domains defined as transit habitat occupied by post-smolts during their first two months at sea (specific domains). Green: Space-time domains corresponding to the habitat occupied by salmon in the later phase of the first year at sea, associated with feeding areas, common to all SU within the same CSG (Labrador Sea and the Norwegian Sea for NA and SE CSG respectively) (common domain).

Figure 4: Left panel: Large scale component trends (medians of marginal posterior distributions and 95\% credibility interval (shaded area)) and individual time-series medians for each SU estimated. (a) Global component and the 13 SU (c) NA component and NA SU (e) SE component and SE SUs. Right panel: Synchronicity indices ICC quantifying the proportion of variance captured by the average trend for each SU within the global component (b), the NA CSG (d) and the SE CSG (f). The average ICC (ICCm) is indicated by the thick line. The thick line corresponds to the median of the ICCm and the shaded area represent the $95 \%$ credibility interval.

Figure 5: Time series of environmental covariates: Sea Surface Temperature in NA (a) and SE (b); Primary Production in NA (c) and SE (d). For (a) to (d): time series defined in the common space-time domains (green color) and time series defined in the specific space-time domains (color range from pink to maroon); (e) standardized Atlantic Multidecadal Oscillation (AMO); and (f) standardized North Atlantic Oscillation Index (NAOI).

Figure 6: Regression coefficients ((a)-(f)) and fraction of temporal variation of post-smolt survival accounted for by effect of environmental covariates ((g)-(l)) defined in the specific space-time domains ((a) \& (g)) (PP), ((b) \& (h)) (SST), in the CSG space-time domains ((c) \& (i)) (PP), ((d) \& (j)) (SST) ((e) \& (k)) (AMO), ((f) \& (l)) (NAOI). Left panels: marginal posterior distributions for the regression coefficients. Thick point is the median, and the different thicknesses of lines represent the $50 \%$, the $75 \%$ and the $95 \%$ posterior credibility intervals. Right panels: fraction of variation accounted for by the covariates. $C_{T O T}$ is the average fraction captured by the covariates when considered over all stock units (red). Blue, green, 
and orange barplots represent the contribution of environmental covariates to the between year variance at the globalscale $\left(\Delta_{\delta}\right)$, CSG-scale $\left(\Delta_{\alpha_{g}}\right)$ and specific scale $\left(\Delta_{\varepsilon_{r}}\right)$ respectively.

This article is protected by copyright. All rights reserved 


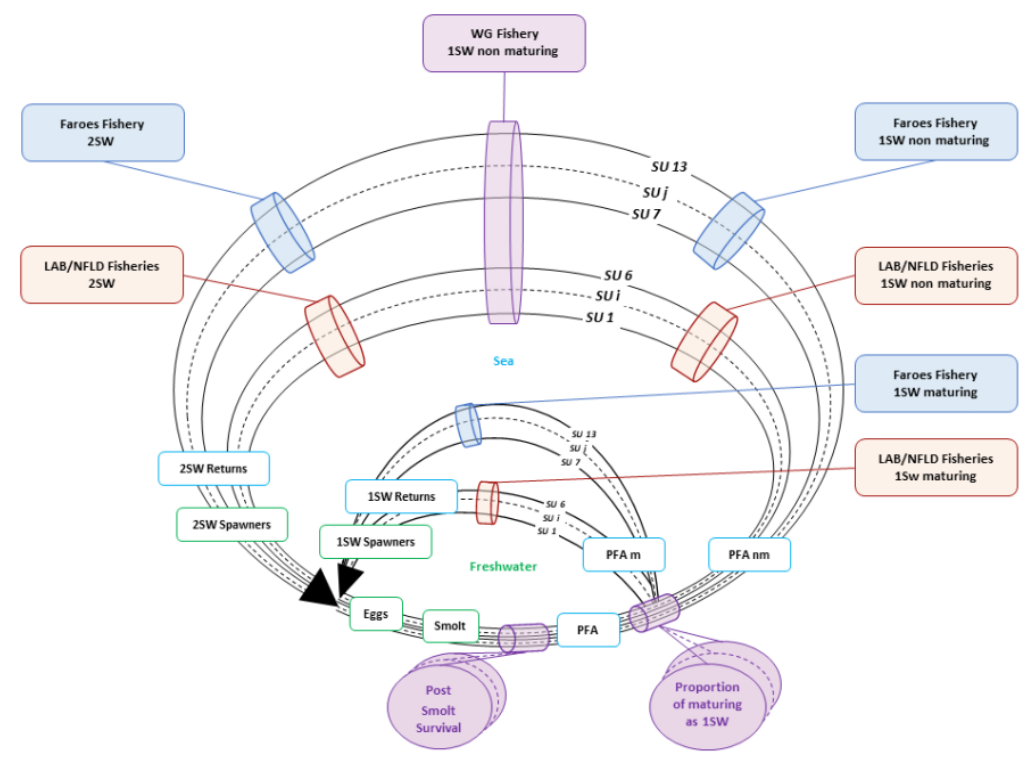

gcb_14913_f1.png

This article is protected by copyright. All rights reserved 


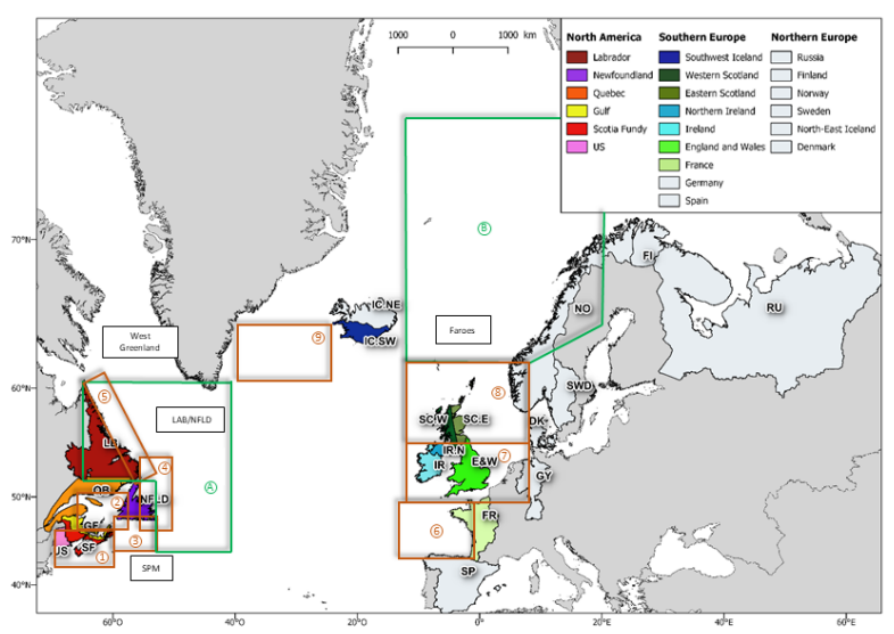

gcb_14913_f2.png

This article is protected by copyright. All rights reserved 


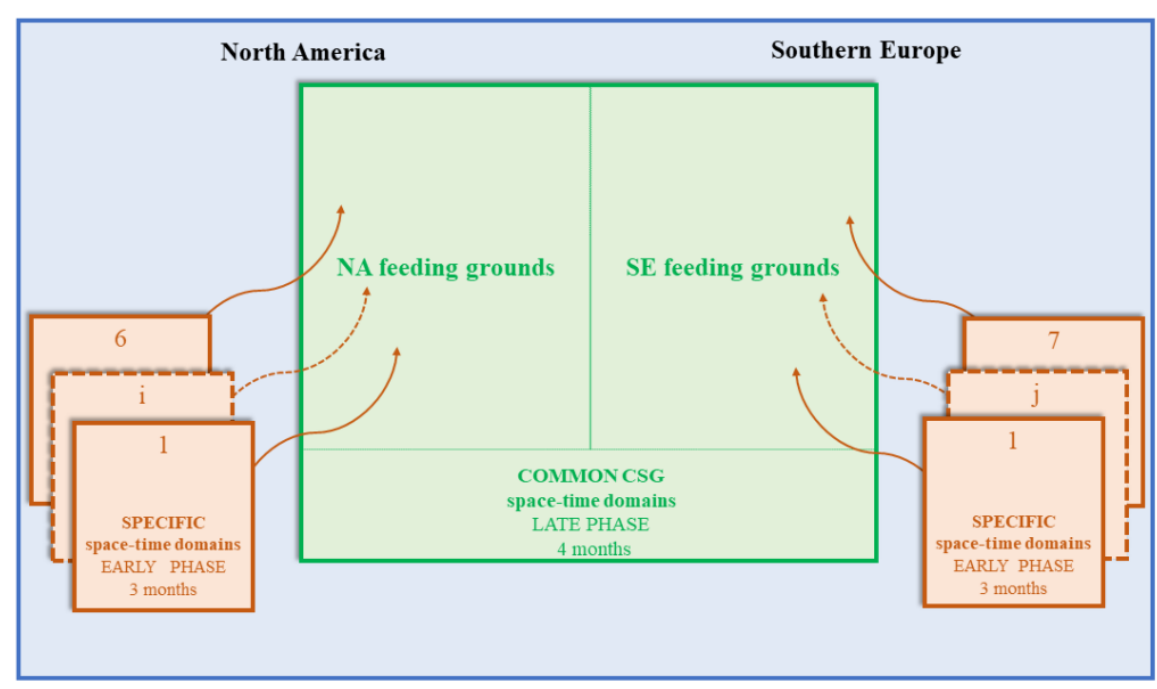

gcb_14913_f3.png 
(a)

$\delta$ : Global scale component

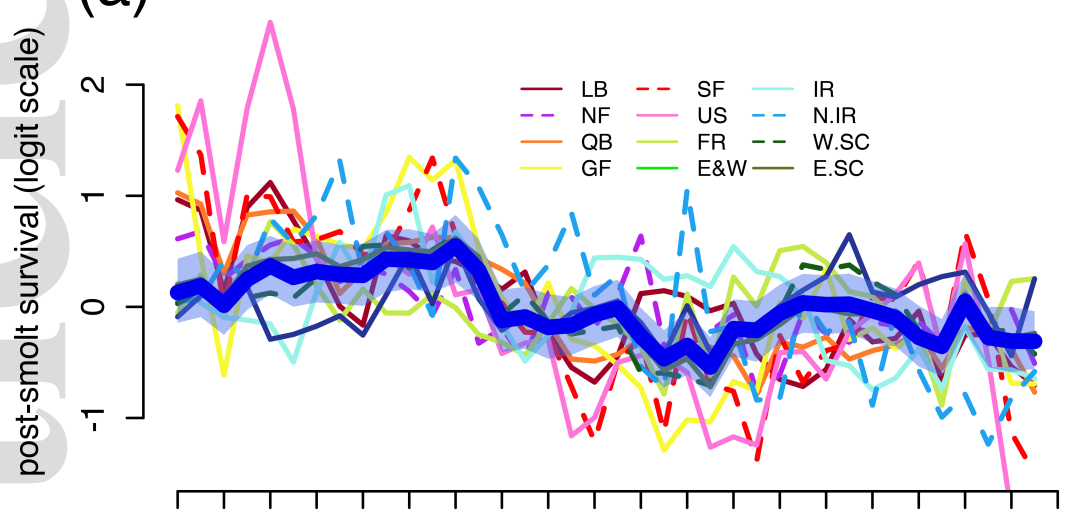

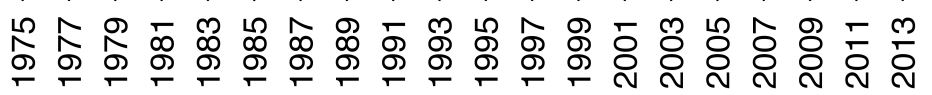

(c) $\delta+\alpha_{N A}$ : NA component

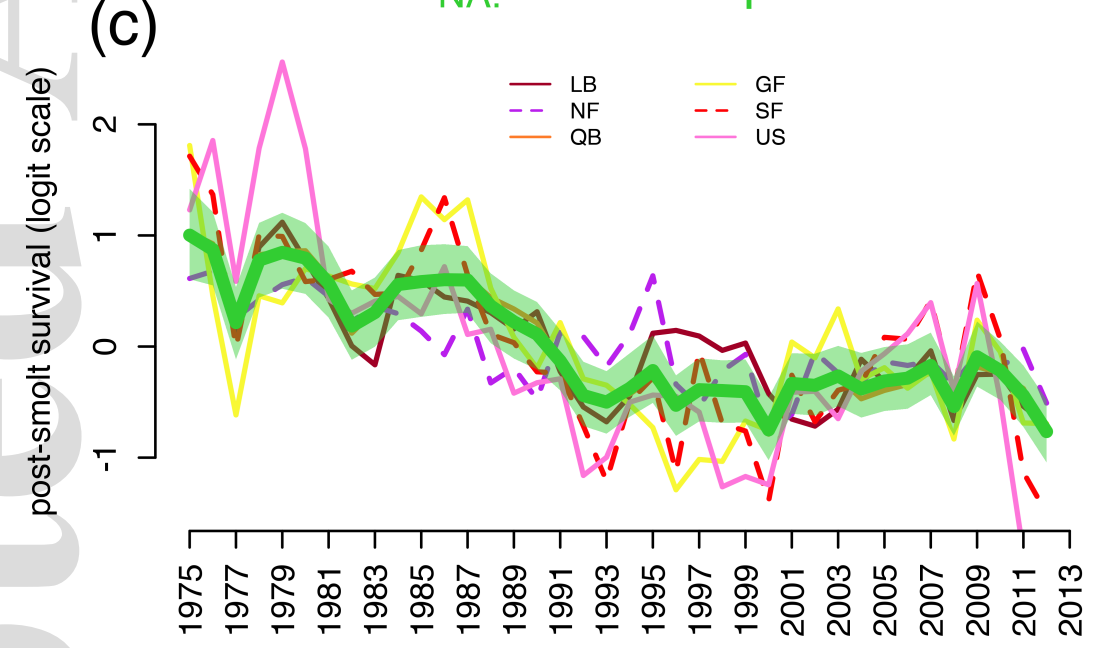

(e)

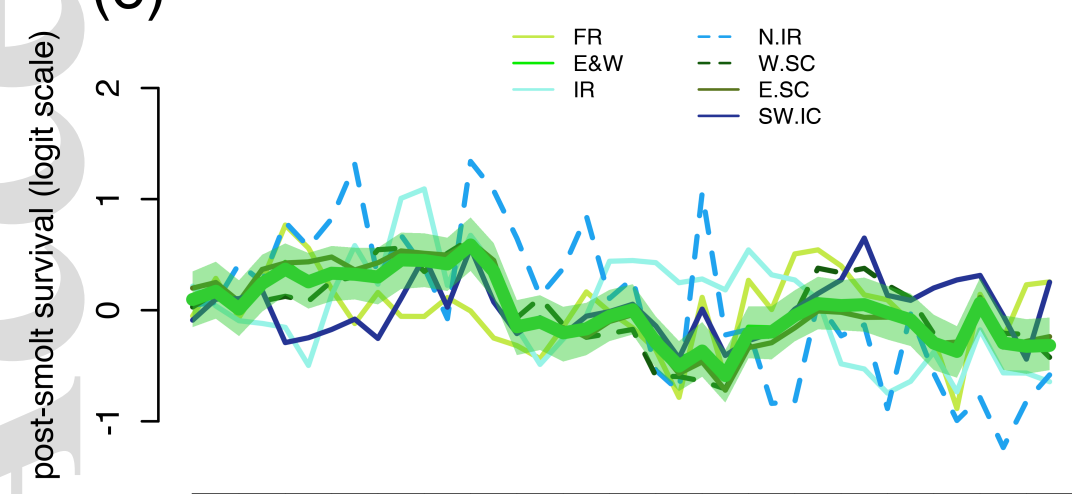

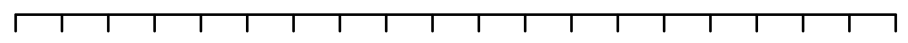

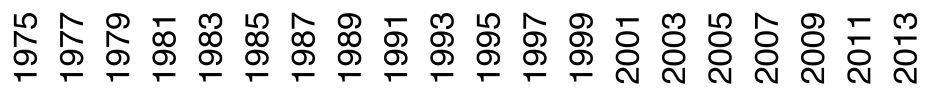
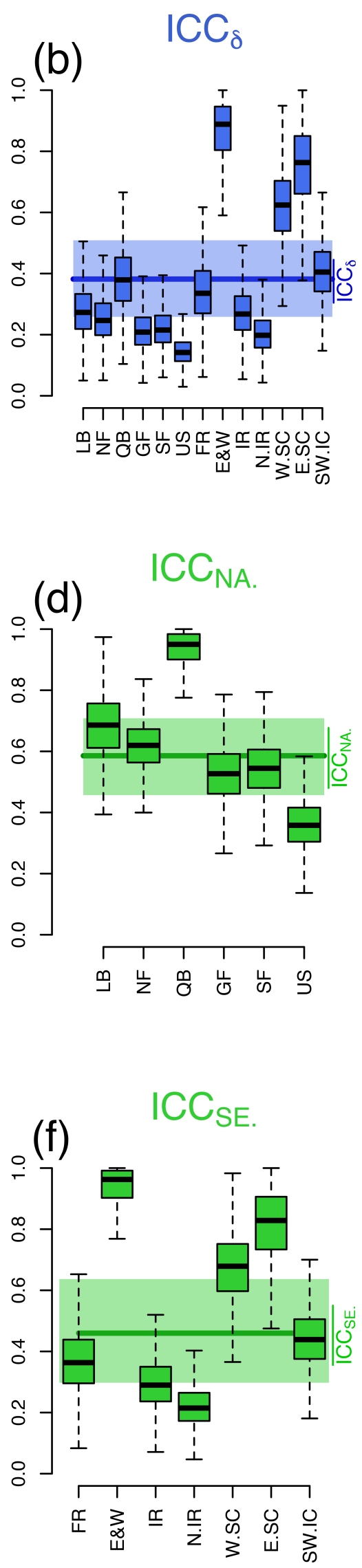


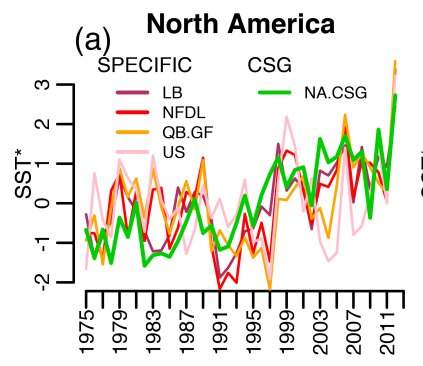

(b) Southern Europe
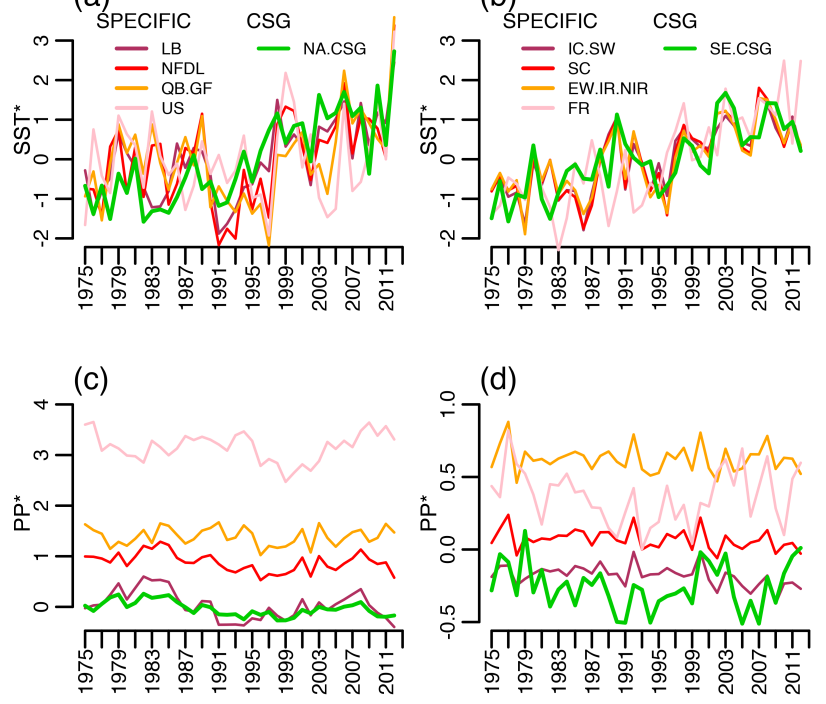

(e)

Large scale climate indices

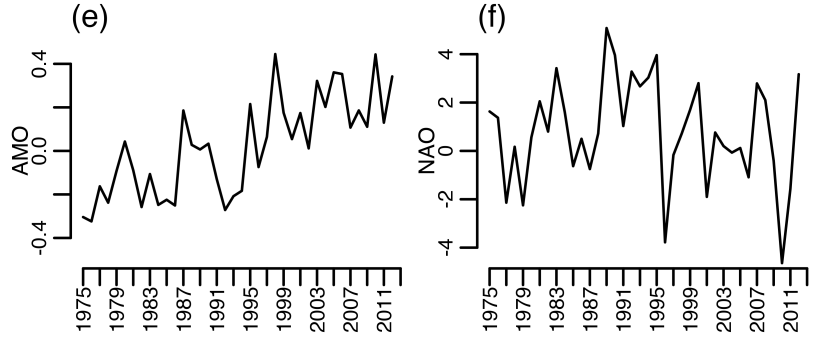

$$
\text { gcb_14913_f5.png }
$$



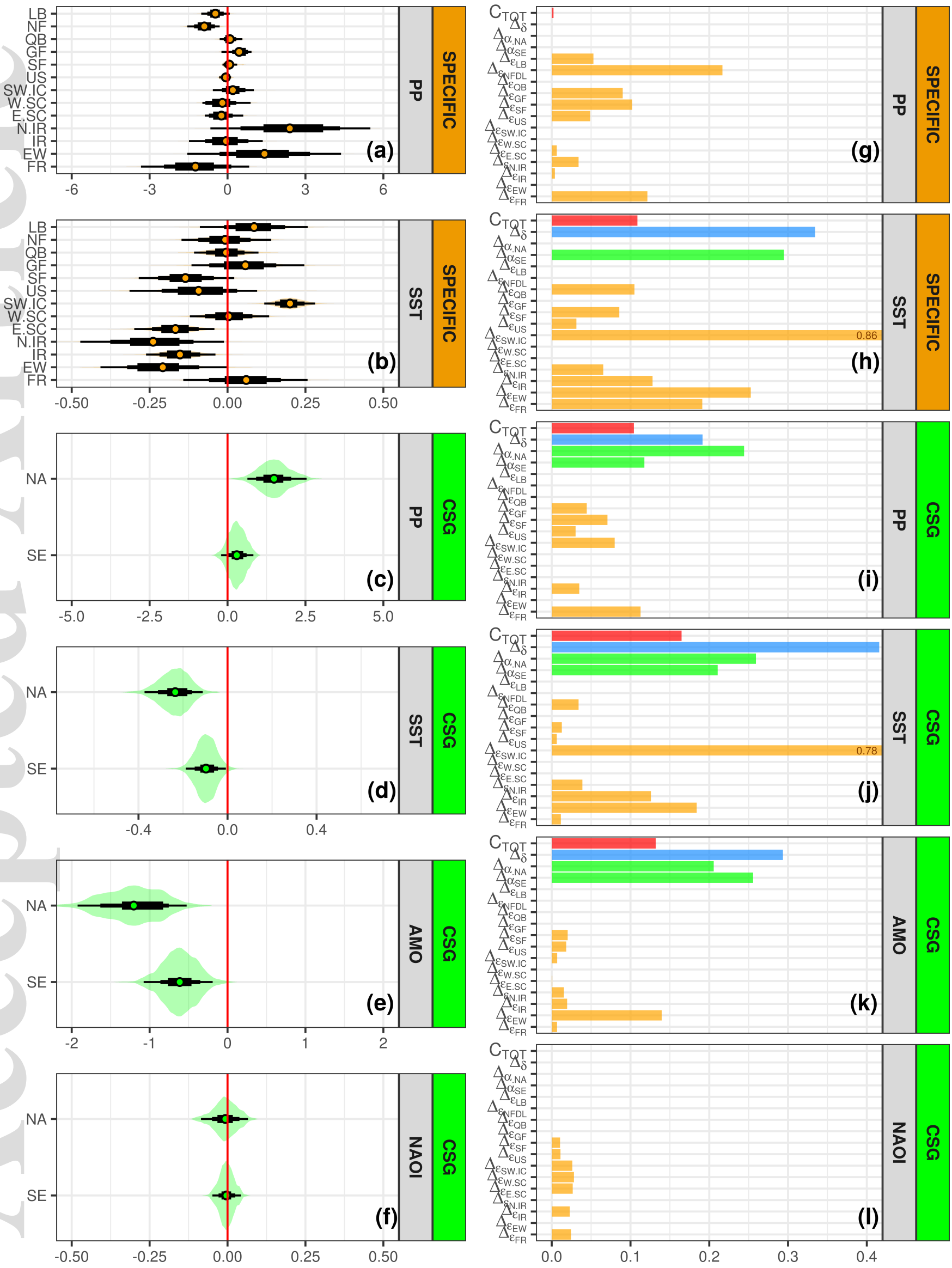

$\mathrm{C}_{\mathrm{TQT}}-$

$\Delta_{\alpha, N A}^{\alpha}$

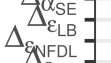

$\bar{d}_{\varepsilon_{\mathrm{GB}}}$

$\Delta_{\varepsilon_{\text {US }}}^{\varepsilon_{\text {SF }}}$

$S_{\text {E.SC }}^{e-s .}$

$\Delta_{\mathcal{E N}_{\mathrm{N}} \mathrm{IR}}$

$\Delta_{\varepsilon_{F R}}^{\varepsilon_{I R}}$

z오

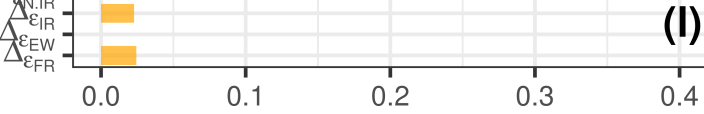

